\title{
A novel pathway of ceramide metabolism in Saccharomyces cerevisiae
}

\author{
Natalia S. VOYNOVA*, Christine VIONNET*, Christer S. EJSING ${ }^{*}$ and Andreas CONZELMANN*1 \\ ${ }^{*}$ Division of Biochemistry, Department of Biology, University of Fribourg, Chemin du Musée 10, Fribourg, CH-1700, Switzerland, and †Department of Biochemistry and Molecular \\ Biology, University of Southern Denmark, Campusvej 55, DK-5230 Odense M, Denmark
}

The hydrolysis of ceramides in yeast is catalysed by the alkaline ceramidases Ypc1p and Ydc1p, two highly homologous membrane proteins localized to the ER (endoplasmic reticulum). As observed with many enzymes, Ypclp can also catalyse the reverse reaction, i.e. condense a non-esterified fatty acid with PHS (phytosphingosine) or DHS (dihydrosphingosine) and thus synthesize ceramides. When incubating microsomes with $\left[{ }^{3} \mathrm{H}\right]$ palmitate and PHS, we not only obtained the ceramide PHS $-\left[{ }^{3} \mathrm{H}\right] \mathrm{C}_{16: 0}$, but also a more hydrophobic compound, which was transformed into PHS- $\left[{ }^{3} \mathrm{H}\right] \mathrm{C}_{16: 0}$ upon mild base treatment. The biosynthesis of a lipid with similar characteristics could also be observed in living cells labelled with $\left[{ }^{14} \mathrm{C}\right]$ serine. Its biosynthesis was dependent on the diacylglycerol acyltransfereases Lro1p and Dga1p, suggesting that it consists of an acylceramide. The synthesis of acylceramide could also be monitored using fluorescent NBD (7-nitrobenz-2-oxa-1,3diazole)-ceramides as an acceptor substrate for microsomal assays. The Lrolp-dependent transfer of oleic acid on to NBDceramide was confirmed by high-resolution Fourier transform and tandem MS. Immunopurified Lro1p was equally able to acylate NBD-ceramide. Lrolp acylates NBD-ceramide by attaching a fatty acid to the hydroxy group on the first carbon atom of the longchain base. Acylceramides are mobilized when cells are diluted into fresh medium in the presence of cerulenin, an inhibitor of fatty acid biosynthesis.

Key words: acylceramide, acyltransferase, detoxification, DGA1, LRO1, triacylglycerol.

\section{INTRODUCTION}

Sphingolipids are essential structural components of cell membranes that also have messenger functions regulating the proliferation, survival and death of cells. The yeast sphingolipids consist of LCBs (long-chain bases), LCB-1phosphates, ceramides, IPCs (inositolphosphorylceramides) and their mannosylated derivatives [1]. Sphingolipid synthesis begins in the ER (endoplasmic reticulum), where serine palmitoyltransferase uses serine and a fatty acyl-CoA to make 3-oxo-sphinganine, which is then converted into DHS (dihydrosphingosine; sphinganine). DHS is then hydroxylated at C4 by Sur2p yielding its 4-hydroxy derivative PHS (phytosphingosine; 4-hydroxysphinganine). Ceramides are made in the ER, whereas the biosynthesis of IPCs and more complex sphingolipids occurs in the Golgi [2]. Thus ceramide is an intermediate in the formation of complex sphingolipids. In mammalian cells, many reports have documented the important role of ceramides as signalling molecules [3].

In the yeast Saccharomyces cerevisiae the biosynthesis of ceramide is mainly achieved by the acyl-CoA-dependent ceramide synthase $L A G 1$ and its close homologue $L A C 1$, formerly known as longevity assurance genes $[4,5]$. Ceramides then can follow any one of several pathways, as indicated in Figure 1. Ceramides can also be hydrolysed by Ypc1p and Ydc1p, two alkaline ceramidases that display more then $50 \%$ of homology over their entire amino acid sequence and reside in the ER, where Lag $1 \mathrm{p}$ and Lac1p are also localized. Ypc1p catalyses, in vitro and in certain instances in vivo, the reverse reaction, i.e. the condensation of non-esterified fatty acids with PHS or DHS [6]. Ydc1p, in contrast with Ypc1p, has been shown to hydrolyse only DHS-containing ceramides and exhibits only very weak reverse activity in vitro, but seems to be able to work in the reverse direction in vivo [5,7-9].

Like many organisms, yeast store neutral lipids in the form of LDs (lipid droplets). Synthesis of neutral lipids and thus LD biogenesis in yeast is mediated by two acylCoA:sterol acyltransferases, Are1p and Are2p, and by Lro1p and Dga1p, which acylate DAG (diacylglycerol) to produce TAG (triacylglycerol). All of these enzymes are present in the ER, except for Dgalp which has a much higher specific activity in LDs than the ER [10-12]. LRO1 accounts for the major part of TAG biosynthesis in exponentially growing cells and is homologous with the mammalian LCAT (lecithin cholesterol acyltransferase) $[13,14]$. Lro1p transfers a fatty acid from the $s n-2$ position of PE (phosphatidylethanolamine) or PC (phosphatidylcholine) on to DAG, whereas Dga1p transfers the fatty acid from acylCoA on to DAG [10,13-15]. Neutral lipid synthesis and storage are dispensable for the viability of $S$. cerevisiae because an are $1 \Delta$ are $2 \Delta$ dgal $\Delta$ lrol $\Delta$ quadruple mutant is viable, makes no storage lipids and lacks detectable LDs $[14,16]$.

In the present paper we report on the enzymatically mediated acylation of ceramides, a process which physiologically may allow for ceramide storage or detoxification.

\section{EXPERIMENTAL}

\section{Strains, growth conditions and materials}

$S$. cerevisiae strains used are listed in Table 1 and plasmids used are listed in Table 2. Mutant strains were generated using standard methods for crossing of single mutants, for plasmid transfection or gene disruption using deletion cassettes generated

Abbreviations used: CHX, cyclohexamide; DAG, diacylglycerol; DDQ, 2,3-dichloro-5,6-dicyanobenzoquinone; DHS, dihydrosphingosine; ER, endoplasmic reticulum; FT-MS, Fourier transform MS; GFP, green fluorescent protein; IPC, inositolphosphorylceramide; LCAT, lecithin cholesterol acyltransferase; LCB, long-chain base; LD, lipid droplet; MMA, monomethylamine; MS/MS, tandem MS; NBD, 7-nitro-2-oxa-1,3-diazole; PC, phosphatidylcholine; PE, phosphatidylethanolamine; PHS, phytosphingosine; PLA $A_{2}$, phospholipase $A_{2} ;$ TAG, triacylglycerol; WT, wild-type; YPD, $1 \%$ $(\mathrm{w} / \mathrm{v})$ yeast extract/2\% (w/v) peptone/2\% (w/v) glucose; YPG, $1 \%(\mathrm{w} / \mathrm{v})$ yeast extract/2\% (w/v) tryptone/ $2 \%(\mathrm{w} / \mathrm{v})$ galactose.

To whom correspondence should be addressed (email andreas.conzelmann@unifr.ch). 
Table 1 Yeast $\boldsymbol{S}$. cerevisiae strains

\begin{tabular}{|c|c|c|}
\hline Strains & Genotype & Reference \\
\hline BY4742 & MAT $\alpha$ his3 $\Delta 1$ leu2 $\Delta 0$ lys $2 \Delta 0$ ura3 $\Delta 0$ & EUROSCARF \\
\hline WT.vector (FBY5218) & As BY4742 but also containing pRS415 & The present study \\
\hline Iro1 & As BY4742, but Iro1::kanMX and also containing pYPC1-LEU2 & The present study \\
\hline Iro1. YPC1.LR01 (FBY5277) & As BY4742, but Iro1::kanMX and also containing pYPC1-URA3 and pLR01-LEU2 & The present study \\
\hline ypc1 $\Delta y d c 1 \Delta$. vector (FBY5322) & MAT $\alpha$ can1 $\Delta:: S T E 2 p r-S p \_h i s 5$ lyp1 $\Delta$ his3 $\Delta 1$ leu2 $\Delta 0$ ura3 $\Delta 0$ met15 $\Delta 0$ ypc1::LEU2 ydc1::natMX containing pNP302 & The present study \\
\hline ypc1 1 ydc1 1 . YPC1 (FBY5321) & MAT $\alpha$ can1 $\Delta::$ STE2pr-Sp_his5 lyp1 $\Delta$ his3 $\Delta 1$ leu2 $\Delta 0$ ura3 $\Delta 0$ met15 $\Delta 0$ ypc1::LEU2 ydc1::natMX containing pYPC1-URA3 & The present study \\
\hline are1 $\triangle$ are2 $\Delta /$ ro1 $\Delta . D G A 1$ (RSY3292) & As BY4742 but are1::kanMX are2::kanMX trp1::URA3 Iro1::IoxP GAL1 1UAS-GFP-DGA1::HIS3 & [12] \\
\hline are1 $\Delta$ are2 $\Delta d g a 1 \Delta . L R 01$ (RSY3202) & As BY4742 but are1::kanMX are2::kanMX trp1::URA3 dga1::IoxP GAL1 1uAS -GFP-LR01::HIS3 & R. Schneiter \\
\hline are1 $\Delta$ Iro1 $\Delta$ dga1 $\Delta . A R E 2$ (RSY3492) & As BY4742 but Iro1::kanMX dga1::IoXP are1::IOXP GAL1 UAS $_{\text {ARE2:::HIS3 }}$ & R. Schneiter \\
\hline $\operatorname{scs} 7 \Delta$ & BY4742, but scs7::kanMX & EUROSCARF \\
\hline isc1 $1 \Delta$ & BY4742, but isc1::kanMX & EUROSCARF \\
\hline are1 $\Delta$ are2 $\Delta d g a 1 \Delta . L R 01 . D G A 1(R S Y 4360)$ & As BY4742 but are1::kanMX are2::kanMX trp1::URA3 dga1::IoxP GAL1 UAS-LR01::TRP1 containing pGAL1-GFP-DGA1-URA3 & R. Schneiter \\
\hline
\end{tabular}

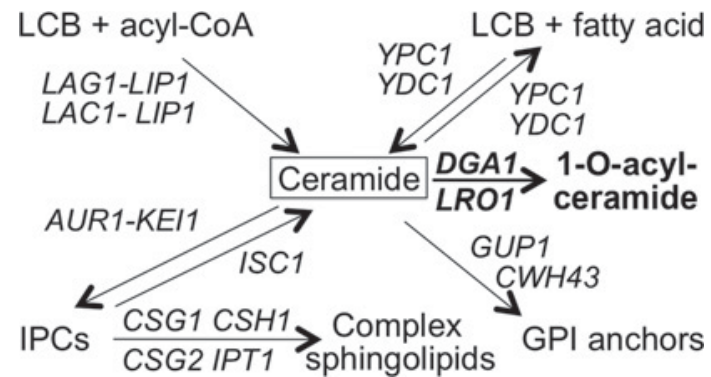

Figure 1 Ceramide biosynthesis and utilization in yeast

The various metabolic pathways generating and consuming ceramides are shown. Gene names are in italic. The novel pathway generating acylceramides described in the present paper is in bold.

Table 2 Plasmids

\begin{tabular}{lll}
\hline Plasmid & Details & Reference \\
\hline pRS415 & CEN ARS LEU2 & {$[45]$} \\
pNP302 & CEN ARS URA3, ADH1 promoter & C. De Virgilio \\
pNP308 & CEN ARS LEU2, ADH1 promoter & C. De Virgilio \\
pYPC1-LEU2 & YPC1 in pNP308 & The present study \\
pYPC1-URA3 & YPC1 in pNP302 & The present study \\
pLR01-LEU2 & LR01 behind its natural promoter in pRS415 & R. Schneiter \\
& & \\
\hline
\end{tabular}

by PCR. Cells were grown on rich medium $\{$ YPD $[1 \%(w / v)$ yeast extract $/ 2 \%(\mathrm{w} / \mathrm{v})$ peptone/2\% (w/v) glucose] or YPG [1\% $(\mathrm{w} / \mathrm{v})$ yeast extract $/ 2 \%(\mathrm{w} / \mathrm{v})$ tryptone/ $2 \%(\mathrm{w} / \mathrm{v})$ galactose] $\}$, or synthetic minimal or complete media [YNB (yeast nitrogen base); United States Biological) containing $2 \%(w / v)$ glucose (D) or galactose $(\mathrm{G})$ as a carbon source. All experiments were performed with cells growing exponentially. Where indicated, medium or buffers were supplemented with CHX (cycloheximide), myriocin, cerulenin, palmitate or $\mathrm{L}-\alpha$-PC from egg yolk, all obtained from Sigma. $\left[{ }^{14} \mathrm{C}\right]$ Serine and $\left[{ }^{3} \mathrm{H}\right]$ palmitate were from American Radiolabeled Chemicals. DHS, PHS, fluorescent ceramides $\left(\mathrm{C}_{12}-\right.$ NBD-PHS and $\mathrm{C}_{6}-\mathrm{NBD}-\mathrm{DHS}$; NBD is 7-nitrobenz-2-oxa-1,3diazole) and fatty acyl-CoAs were from Avanti Polar Lipids. $\mathrm{C}_{6}-\mathrm{NBD}-$ sphingosine was from Invitrogen. Monomethylamine $\left(33 \%\right.$ in ethanol) was from Fluka. Dynabeads ${ }^{\circledR}$-Protein G was from Invitrogen. Zymolyase-20T (Arthtrobacter luteus) was from Seikagaku Biobusiness. Mouse monoclonal anti-GFP (green fluorescent protein) antibodies were from Roche Diagnostics. The anti-mouse IgG-peroxidase conjugate was from Sigma.

\section{Construction of plasmids}

To construct plasmids containing $Y P C l$, the open reading frame was amplified by PCR using the oligonucleotides 5'-CCTGGGATCCATGGGAATATTTCGTTGGAACTATCC-3' and 5'CGCCGCGGCCGCTTACTTCTCCTTTTTAACTTC- ${ }^{\prime}$ and genomic DNA from WT (wild-type) BY4742 cells. PCR products were doubly digested with NotI and BamHI and ligated into the similarly digested $\mathrm{pNP} 308$ or $\mathrm{pNP} 302$ vectors to generate $\mathrm{pYPC} 1$ LEU2 and pYPC1-URA3. DNA sequencing of inserts confirmed the correct sequence of $Y P C 1$.

\section{Protein analysis}

Proteins were extracted by mild alkali treatment and subsequent boiling of cells in a standard electrophoresis loading buffer [17]. Proteins were resolved by SDS/PAGE and detected by Western blotting using standard procedures.

\section{Mass spectrometric lipid analysis}

Microsomes were extracted with chloroform/methanol [2:1 (v/v)] [18]. Lipid extracts were analysed in negative-ion mode by direct infusion MS using an LTQ Orbitrap XL mass spectrometer equipped with the automated nanoflow ion source Triversa NanoMate (Advion Biosciences) [18]. $\mathrm{C}_{6}-\mathrm{NBD}-\mathrm{DHS}$ and its acyl-derivatives were detected by high-resolution FT-MS (Fourier transform MS) using a target mass resolution of 100000 . In addition, the identity of detected $\mathrm{C}_{6}-\mathrm{NBD}-\mathrm{DHS}$ and acyl-derivatives was confirmed by ion-trap MS/MS (tandem MS) analysis.

\section{Metabolic labelling of cells with $\left[{ }^{14} \mathrm{C}\right]$ serine, lipid extraction, mild base treatment and TLC}

Cells were grown in synthetic minimal medium. Then $3.0 D_{600}$ units of exponentially growing cells $(3 \mathrm{ml}$ of a culture having a $D_{600}$ of 1.0) were harvested and resuspended in $250 \mu \mathrm{l}$ of the same medium supplemented with $10 \mu \mathrm{g} / \mathrm{ml} \mathrm{CHX.} \mathrm{After} 10 \mathrm{~min}$ of pre-incubation, $4 \mu \mathrm{Ci}$ of $\left[{ }^{14} \mathrm{C}\right]$ serine was added and cells were incubated for $40 \mathrm{~min}$ at $30^{\circ} \mathrm{C}$. Then the samples were diluted with $750 \mu \mathrm{l}$ of fresh minimal medium supplemented with CHX and labelling was continued for a further 120 min. Labelling 
was terminated by adding sodium azide and sodium fluoride (10 mM final concentrations) and chilling cells on ice. Cells were resuspended in chloroform/methanol $[2: 1(\mathrm{v} / \mathrm{v})]$ and broken with glass beads in the cold. The extract was kept apart and the pellet was re-extracted sequentially with chloroform/methanol [1:1 (v/v)] and ethanol/water/diethyl ether/putridine/25\% ammonium hydroxide (15:15:5:1:0.018, by vol.), which achieves quantitative extraction of all complex sphingolipids [19]. Extracts were combined and solvent was evaporated under vacuum in a rotary evaporator. Incorporation into lipids usually amounted to $5 \%$ of radioactivity added. Where indicated, lipids were subjected to mild base hydrolysis with sodium hydroxide or MMA (monomethylamine). For this, lipids were resuspended in $200 \mu \mathrm{l}$ of chloroform/methanol/water (10:10:3, by vol.), $40 \mu 1$ of $0.6 \mathrm{M}$ sodium hydroxide in methanol (final concentration of $0.1 \mathrm{M}$ ) was added, and samples were incubated for $1 \mathrm{~h}$ at $37^{\circ} \mathrm{C}$. Hydrolysis was stopped with $40 \mu \mathrm{l}$ of $0.8 \mathrm{M}$ acetic acid in methanol. Control samples were incubated on ice and at the end of the incubation supplemented with $40 \mu \mathrm{l}$ of $0.8 \mathrm{M}$ acetic acid plus $40 \mu \mathrm{l}$ of $0.6 \mathrm{M}$ sodium hydroxide. The desalted lipids were resolved by ascending TLC on silica gel plates. Alternatively, lipids were resuspended in $400 \mu \mathrm{l}$ of MMA ( $33 \%$ in ethanol) or, as a negative control, in methanol, and incubated at $53^{\circ} \mathrm{C}$ for $1 \mathrm{~h}$. Then, solvents were evaporated under vacuum. All lipids were resolved by ascending TLC on silica gel plates after having been desalted by Folch partitioning as described previously [20]. Unless indicated otherwise, extracts of microsomes were developed with solvent 1 (chloroform/methanol $/ 25 \%$ ammonium hydroxide, 9:2:0.5, by vol.) and extracts from metabolically labelled cells were developed with solvent 2 (chloroform/methanol/2 $\mathrm{M}$ ammonium hydroxide, 40:10:1, by vol.). When the untreated and deacylated lipid extract was run side by side, material from an equivalent number of cells was spotted, whether we analysed extracts from metabolic labellings or microsomal labelling reactions (see below). Radioactivity was detected and quantified by one- and two-dimensional radioscanning using a Berthold radioscanner and visualized by fluorography or radioimaging using the Bio-Rad Molecular Imager FX. Unless otherwise stated, radioactivity in individual spots was given as the percentage of total radioactivity detected by radioscanning in the corresponding lane, except for acylceramides. In the case of acylceramides, the counts of residual mild-base-resistant lipid co-migrating with acylceramides, as well as of an occasional trace of material co-migrating with fatty acids, were deducted from the acylceramide signal as follows:

Percentage of acylceramides

$$
\begin{aligned}
= & (\text { acylceramide untreated }- \text { acylceramide deacylated } \\
& + \text { fatty acid deacylated }] / \text { total counts untreated }) \times 100 .
\end{aligned}
$$

\section{Preparation of microsomes}

Microsomes were prepared from yeast cells grown in synthetic complete media. Briefly, as described previously [6], cells were homogenized in a lysis buffer containing $25 \mathrm{mM}$ Tris/ $\mathrm{HCl}$ (pH 7.4), $1 \mathrm{mM}$ PMSF and Roche protease inhibitor cocktail. Unbroken cells and cell debris were removed by centrifugation at $500 \mathrm{~g}$ for $5 \mathrm{~min}$. The membrane fraction was sedimented by centrifuging the supernatant at $16000 \mathrm{~g}$ for $40 \mathrm{~min}$ at $4{ }^{\circ} \mathrm{C}$. The microsomes were resuspended in assay buffer A containing $25 \mathrm{mM}$ Tris/ $\mathrm{HCl}$ (pH 8.0), $5 \mathrm{mM} \mathrm{CaCl} \mathrm{Cl}_{2}$ and $1 \mathrm{mM} \mathrm{PMSF}$. In most experiments, boiled microsomes $\left(100^{\circ} \mathrm{C}\right.$ for $\left.10 \mathrm{~min}\right)$ were used as a negative control. Protein concentrations were determined using Bradford reagent (Bio-Rad Laboratories).

\section{Microsomal assay of reverse ceramidase using $\left[{ }^{3} \mathrm{H}\right]$ palmitate}

The reverse ceramidase activity was measured as described previously [21] with the following modifications: $10 \mu 1$ of $1 \mathrm{mM}$ PHS or DHS, $3 \mu \mathrm{Ci}$ of $\left[{ }^{3} \mathrm{H}\right]$ palmitate $(60 \mathrm{Ci} / \mathrm{mmol})$ and 0.4 nmol of non-radioactive palmitate were dried under vacuum in a rotary evaporator. Dried lipids were dissolved in $20 \mu 1$ of buffer A by water bath sonication. The reactions were started by adding microsomes corresponding to $50 \mu \mathrm{g}$ of protein to attain a final volume of $50 \mu \mathrm{l}$. Samples were incubated at $30^{\circ} \mathrm{C}$ for $1 \mathrm{~h}$ at $300 \mathrm{rev} . / \mathrm{min}$ on a tube shaker. The reactions were terminated by adding $300 \mu \mathrm{l}$ of chloroform/methanol [2:1 (v/v)].

\section{Microsomal assays using NBD-ceramides}

NBD-containing ceramides $\left(\mathrm{C}_{12}-\mathrm{NBD}-\mathrm{PHS}, \mathrm{C}_{6}-\mathrm{NBD}-\mathrm{DHS}\right.$ or $\mathrm{C}_{6}-\mathrm{NBD}$-sphingosine) were bound to BSA using an established procedure [22], which was modified as follows. For ten standard reactions, $100 \mathrm{nmol}$ of NBD-ceramide were dissolved in $20 \mu \mathrm{l}$ of ethanol and added to $200 \mu \mathrm{l}$ of buffer A containing $40 \mathrm{mg} / \mathrm{ml}$ of fatty-acid-free BSA giving an NBD-ceramide to BSA molar ratio of $1: 1$. The solution was incubated on a wheel at $4^{\circ} \mathrm{C}$ for $2 \mathrm{~h}$. Microsomal pellets were dissolved in buffer A supplemented with $10 \mathrm{mg} / \mathrm{ml}$ of fatty-acid-free BSA, the final concentration of microsomal protein being $5.0 \mathrm{mg} / \mathrm{ml}$. The reactions were initiated by adding $50-100 \mu \mathrm{g}$ of microsomes to $10 \mathrm{nmol}$ of NBD-ceramide in a final volume of $50 \mu \mathrm{l}$ containing $10 \mathrm{mg} / \mathrm{ml}$ BSA. Reaction mixtures were incubated at $30^{\circ} \mathrm{C}$ for $2 \mathrm{~h}$ and then stopped by adding $300 \mu \mathrm{l}$ of chloroform/methanol [2:1 (v/v)]. Lipids were extracted, treated or not with mild base, desalted and resolved by TLC. Products of NBD-ceramide conversion were identified as fluorescent bands and quantified with a FluorChem 8900 fluorescence detector (Witec).

\section{Immunopurification of Lro1p-GFP on Dynabeads ${ }^{\circledR}$-Protein G}

RSY3202 cells were grown on YPG media. Cells were collected, treated with zymolyase and spheroplasts were lysed with a Dounce homogenizer in buffer B [20 mM Hepes (pH 6.8), 0.2 M sorbitol, $50 \mathrm{mM}$ potassium acetate, $2 \mathrm{mM}$ EDTA and protease inhibitors]. Microsomes were sedimented by centrifugation at $16000 \mathrm{~g}$ for $30 \mathrm{~min}$ at $4{ }^{\circ} \mathrm{C}$ and solubilized in buffer B with $0.5 \%$ Triton X-100 for 30 min on ice whereupon non-solubilized material was removed by centrifugation. Next, $4 \mu \mathrm{g}$ of mouse anti-GFP antibodies were bound to $50 \mu 1(1.5 \mathrm{mg})$ of Dynabeads and the washed beads were incubated with $500 \mu \mathrm{g}$ of solubilized microsomal protein for $30 \mathrm{~min}$ at room temperature $\left(25^{\circ} \mathrm{C}\right)$ on a rotating wheel. Beads were sedimented using a magnet, the supernatant containing non-bound proteins was removed and the beads were washed three times with $0.5 \%$ Triton X-100 in PBS using magnetic sedimentation. Acylceramide synthesis was measured in a final volume of $90 \mu \mathrm{l}$ for $2 \mathrm{~h}$ at room temperature. The assay contained buffer A, BSA $(10 \mathrm{mg} / \mathrm{ml}), \mathrm{PC}(450 \mu \mathrm{M})$, $\mathrm{C}_{6}-\mathrm{NBD}-\mathrm{DHS}(50 \mu \mathrm{M})$, a final concentration of $0.5 \%$ Triton X-100 and $20 \mu \mathrm{l}$ of Dynabeads-Lro1p-GFP conjugate or supernatant containing non-bound proteins. For protein determination, purified Lro1p-GFP was eluted from beads at pH 2.5.

\section{RESULTS}

\section{In vitro microsomal assay of ceramide synthase activity reveals Lro1p-dependent ceramide esterification}

As described previously [6], reverse ceramidase activity of Ypc1p can be measured by incubating microsomes with $\left[{ }^{3} \mathrm{H}\right]$ palmitate and non-radioactive LCBs (Figures 2A and $2 \mathrm{~B}$ ). The $R_{\mathrm{f}}$ of 

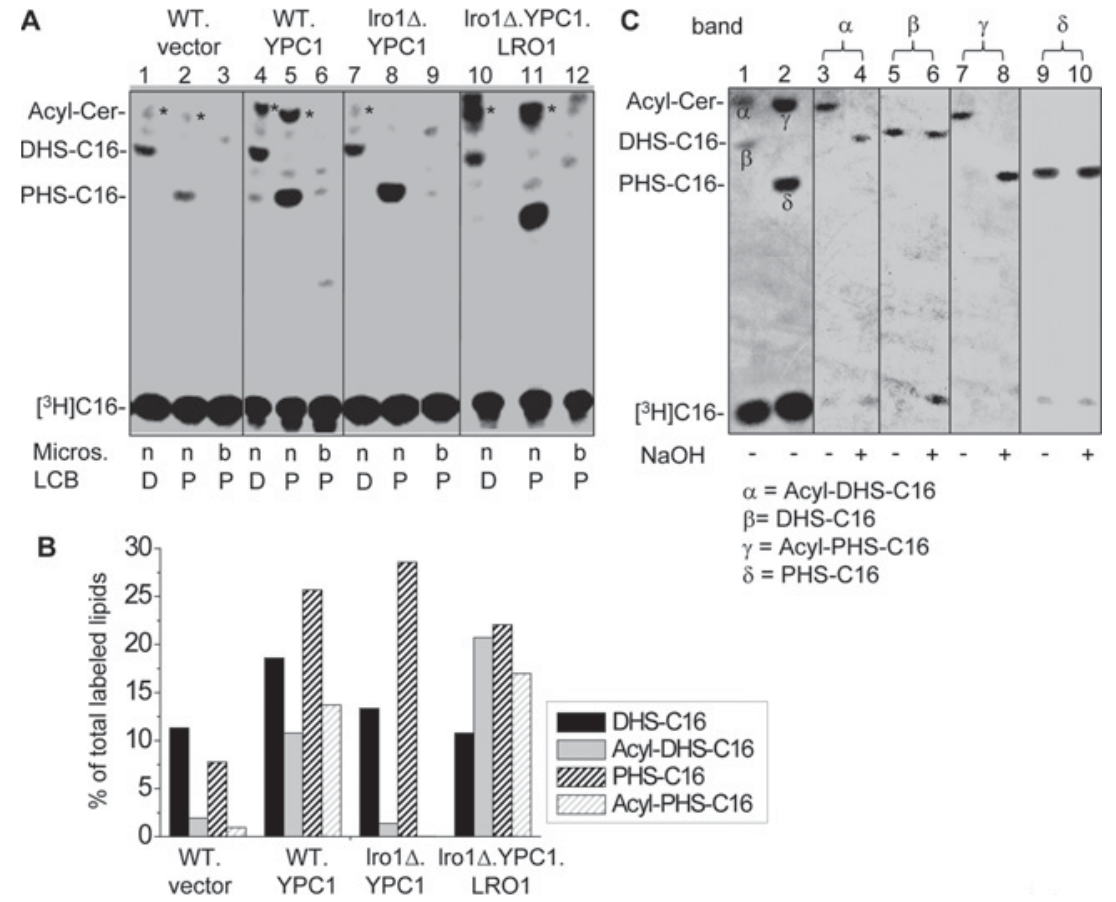

Figure 2 Lro1p-dependent ceramide esterification in microsomes

(A) Microsomes were prepared from BY4742 (WT) and Iro1 $\Delta$ cells carrying an empty vector or vectors with open reading frames of the genes indicated after the dots. The reverse activity of Ypc1p was measured by incubating native $(n)$ or boiled (b) microsomes with [ ${ }^{3} \mathrm{H}$ ]palmitate and DHS (D) or PHS (P) as substrates. Lipids were extracted, resolved by TLC and quantified by radioscanning Presumed acylceramides are marked with an asterisk. A representative experiment from three experiments, all giving the same result, is shown. (B) Counts present in ceramides and putative acylceramides of $(\mathbf{A})$ were quantified by radioscanning and plotted as a percentage of the total counts present in the lane. (C) Presumed acylceramides and ceramides obtained in an in vitro assay with microsomes from WT vector cells using DHS (lane 1) or PHS (lane 2) as substrates were labelled $\alpha, \beta, \gamma$ and $\delta$. These bands were scraped off of the TLC plate, extracted and treated with mild base (sodium hydroxide) or incubated as a control. Hydrolysis products were desalted and separated by TLC. The identity of lipids $\alpha-\delta$ on the basis of this experiment is indicated at the bottom.

ceramides is higher when DHS is used as a substrate than when PHS is used (Figure 2A) and the reaction is much faster when YPC1 is overexpressed (Figure 2A, lanes 1 and 2 compared with lanes 4 and 5, and Figure 2B). (Microsomes from Ypc1poverexpressing cells actually represent an easy and cheap way to generate radiolabelled ceramides.) The reverse ceramidase assay invariably also generated a lipid, which migrated faster than ceramides, pointing to its higher hydrophobicity as compared with ceramides (marked with an asterisk in Figure 2A). We will show below that this species is likely to be a 1-O-acylated ceramide. O-acylated ceramides, as well as ceramides, did not appear when boiled microsomes were used (Figure 2A, lanes 3, 6, 9 and 12). The putative acylceramides were scraped off the TLC plate and treated with sodium hydroxide for saponification (Figure 2C). Upon mild base hydrolysis the presumed acylceramides $\alpha$ and $\gamma$, generated using either DHS or PHS as substrates, yielded the corresponding ceramides (lanes $3,4,7$ and 8); the ceramides themselves $(\beta$ and $\delta$ ) remained stable in the presence of sodium hydroxide (lanes 5, 6, 9 and 10), in agreement with the idea that the lipids marked with an asterisk in Figure 2(A) are acylceramides.

Acylceramide had previously been shown to be made by mammalian cells when microsomes were incubated with $N$-acetyl- $\left[{ }^{3} \mathrm{H}\right]$ sphingosine. The enzyme catalysing the synthesis of $O$-acylceramide in mammals was identified as LPLA2, a soluble lysosomal enzyme working mainly as an acid PLA (phospholipase $\mathrm{A}_{2}$ ), but able to also use ceramide rather than water as an acceptor substrate [23]. A BLAST search showed that its closest homologue in $S$. cerevisiae is Lrolp. Indeed, the synthesis of acylceramides was strongly reduced in lrol $\Delta$ cells, suggesting that $L R O 1$ deletion abolished ceramide acylation (Figure 2A, lanes 7 and 8 compared with lanes 4 and 5). Moreover, the complementation of the lrol $\Delta$ mutant with a single copy plasmid bearing $L R O 1$ under its native promoter completely rescued the acylation of ceramides (Figure 2A, lanes 10 and 11). We wondered whether the second yeast DAG acyltransferase, Dgalp, is also capable of catalysing the synthesis of acylceramide in vitro. To test for this we incubated microsomes of an lrol $\Delta$ strain overexpressing $Y P C 1$ with PHS and $\left[{ }^{3} \mathrm{H}\right]$ palmitate as in Figure 2(A), lane 8 , in order to allow for the formation of labelled ceramides. At the end of the incubation, the reaction was supplemented with different acyl-CoAs as acyl donors for Dga1p and the incubation was continued for a further $1 \mathrm{~h}$ (Supplementary Figure S1 at http://www.BiochemJ.org/ bj/447/bj4470103add.htm). No acylceramide synthesis was detected in this experiment. Although Dgalp is able to acylate ceramides in vivo (see below), reasons for this negative in vitro experiment could be that Ypc1p and Dga1p reside in different subcompartments of the ER, which end up in different microsomes, i.e. that microsomes generating $\left[{ }^{3} \mathrm{H}\right]$ ceramide did not contain enough Dga1p activity. Indeed, Dga1p activity is concentrated in LDs, whereas Lrolp is mainly present in the ER membrane $[10,13]$ (R. Schneiter, personal communication).

\section{NBD-ceramides are acylated in vitro by Lro1p}

To further support the idea that Lrolp is capable of O-acylating ceramides, we tested the capacity of microsomes to acylate fluorescent ceramides. Figure 3(A) demonstrates that up to $25 \%$ of $\mathrm{C}_{12}-\mathrm{NBD}-\mathrm{PHS}$ was acylated by microsomes in a $2 \mathrm{~h}$ assay, 
A
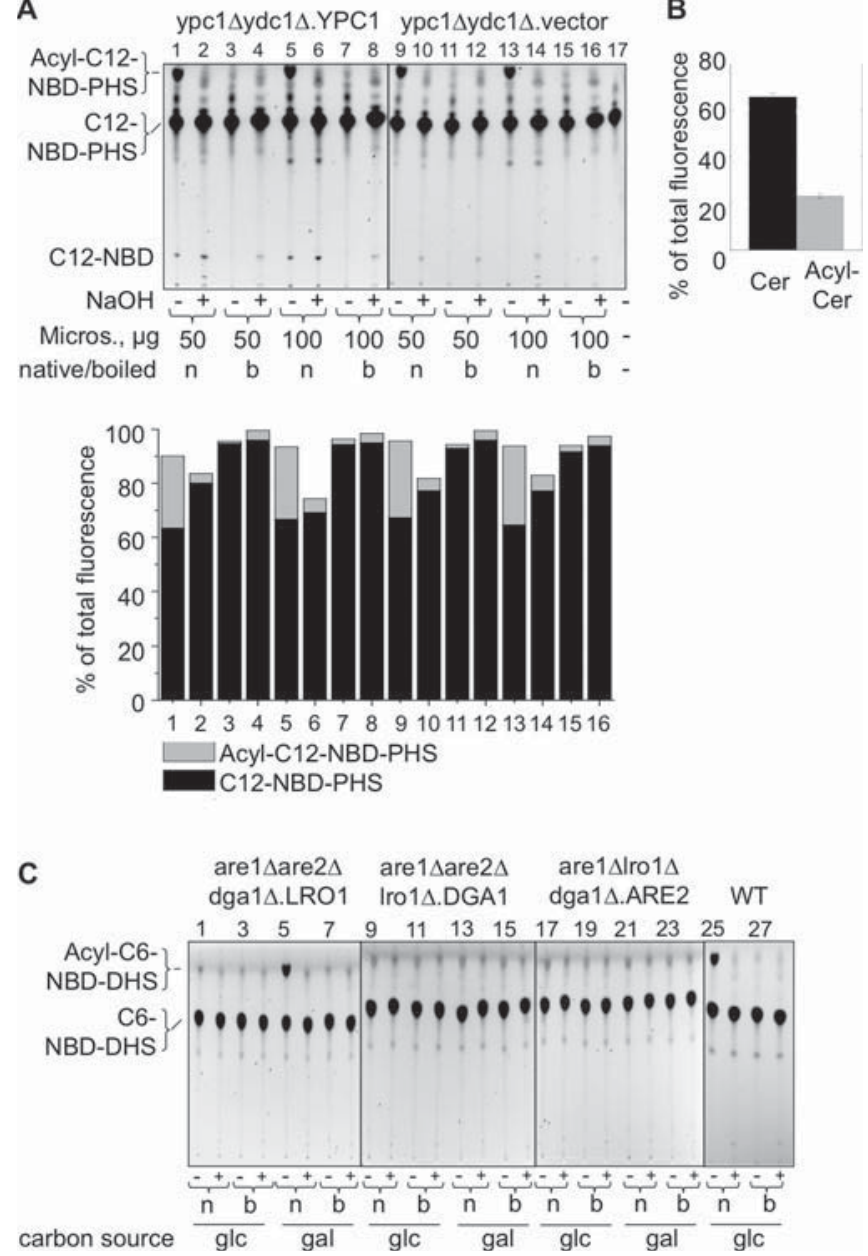

Figure 3 In vitro acylation of NBD-ceramides

(A) Native or boiled microsomes from the indicated strains were incubated for $2 \mathrm{~h}$ at $30^{\circ} \mathrm{C}$ in the presence of $\mathrm{C}_{12}-\mathrm{NBD}-\mathrm{PHS}$, i.e. a ceramide containing an NBD- $\mathrm{C}_{12}$ fatty acid linked to PHS. Lipids were extracted, subjected or not to alkaline hydrolysis and resolved by TLC. Lane 17 contains the $\mathrm{C}_{12}-\mathrm{NBD}-\mathrm{PHS}$ standard as received from Avanti Polar Lipids. The bottom panel represents the quantification of acylceramide and ceramide as a percentage of total fluorescence in each lane. (B) Results from (A) were quantified by averaging fluorescent signals of ceramides and acylceramides of lanes 1, 5, 9 and 13. (C) The indicated mutants were grown on glucose or galactose overnight. Microsomes were labelled as described above, but using $\mathrm{C}_{6}-\mathrm{NBD}-\mathrm{DHS}$, i.e. an NBD- $\mathrm{C}_{6}$ fatty acid linked to the nitrogen of DHS. Microsomes of are1 $\Delta$ are2 $\Delta /$ ro1 $\Delta$.DGA1 and are1 $\Delta$ /ro1 $\triangle$ dga1 $\triangle$.ARE2 strains were additionally supplemented with 5 nmol of $\mathrm{C}_{16: 0}-\mathrm{Co} A$ and $\mathrm{C}_{18: 1}-\mathrm{C} 0 \mathrm{~A}$ respectively. b, boiled; Cer, ceramide; glc, glucose; gal, galactose; $n$, native.

and the extent of this acylation was independent of the presence of Ypclp in the $y p c 1 \Delta y d c 1 \Delta$ background used in the present experiment (Figures 3A and 3B). However, when Ypclp was present, we observed a faint signal, presumably corresponding to $\mathrm{C}_{12}-\mathrm{NBD}$ fatty acid, the product of the ceramidase activity of Ypc1p (Figure 3A, lanes 1 and 5). Qualitatively similar results were obtained with $\mathrm{C}_{6}-\mathrm{NBD}-\mathrm{DHS}$, having a shorter NBD-fatty acid and a different LCB (Figure 3C, lanes 5 and 25, and Figure 4D), whereby no ceramidase activity was detected, possibly because $Y P C l$ was not overexpressed as in Figure 3(A). Acylation, as well as hydrolysis of NBD-ceramides, were observed to a much lower degree when boiled microsomes were used in the reaction (Figure 3A, lanes 3, 7, 11 and 15 compared with lanes 1, 5, 9 and 13, and Figure 3C). The rate of $\mathrm{C}_{12}-\mathrm{NBD}-\mathrm{PHS}$ hydrolysis by Ypclp-containing microsomes in Figure 3(A) amounted to approximately $1 \%$ of total fluorescence (lanes 1 and 5), i.e. it was 6-fold faster than the hydrolysis by yeast microsomes strongly overexpressing human alkaline ceramidase [21]. Although we did not study the kinetics of the metabolism of NBD-ceramides in microsomes, it nevertheless is striking to observe that acylation of this artificial substrate by endogenous levels of Lro1p is 20-fold faster than its hydrolysis by the overexpressed Ypc1p (Figure 3A, lanes 1 and 5), whereby the conditions used for acylceramide synthesis in Figure 3(A) are the same as the ones optimized for measuring Ypc1p-mediated ceramidase activity [6]. Mild base treatment also released approximately $1 \%$ of the amide-bound NBD- $\mathrm{C}_{12}$ fatty acids (Figure 3A, lanes 4, 8, 12 and 16 compared with lanes 3, 7, 11 and 15).

To see which enzymes were responsible for NBD-ceramide acylation, we took advantage of are $1 \Delta$ are $2 \Delta$ lrol $\triangle . D G A 1$, are $1 \triangle$ are $2 \Delta$ dgal $\triangle . L R O 1$ and are $1 \Delta$ lrol $\triangle$ dgal $\triangle$.ARE2 strains, in which the endogenous DGA1, LRO1 or ARE2 gene is placed behind the $G A L 1$-promoter respectively, while all other DAG- or sterol-acyltransferases are deleted. These mutants were cultured on glucose or galactose to repress the expression or induce the overexpression of LRO1, DGA1 or ARE2 respectively. (Are2p accounts for most of the sterol acyltransferase activity, when yeast cells grow in the presence of oxygen [24].) Massive amounts of acylated $\mathrm{C}_{6}-\mathrm{NBD}-\mathrm{DHS}$ were made by microsomes derived from cells overexpressing Lrolp after having been grown on galactose, much more than from cells grown on glucose (Figure 3C, lanes 1 and 5). In contrast, overexpression of Are $2 p$ or of Dga1p did not result in significant microsomal ceramide acylation in the presence of acyl-CoA (Figure 3C).

\section{Identification of the hydroxy group that is acylated by Lro1p}

PHS has hydroxy groups on carbon atoms 1, 3 and 4, and DHS on carbon atoms 1 and 3. To decide whether ceramides are acylated on the carbon atom 1 or 3 of the LCB, we used a procedure previously employed by others [25], which requires the use of ceramides containing sphingosine rather than DHS or PHS. Sphingosine is a dehydrogenated DHS with a $\Delta 4$ double bond (Figure 4A). We found that yeast microsomes efficiently acylate $\mathrm{C}_{6}-\mathrm{NBD}-$ sphingosine (Figure $4 \mathrm{~B}$ ). Acyl- $\mathrm{C}_{6}-$ NBD-sphingosine and unreacted $\mathrm{C}_{6}-\mathrm{NBD}$-sphingosine were scraped from a TLC plate and treated with DDQ (2,3-dichloro5,6-dicyanobenzoquinone) [25]. DDQ oxidizes $\alpha$ - $\beta$-unsaturated alcohols to ketones. Thus an hydroxy group in the $\mathrm{C} 3$ position of sphingosine will be oxidized to a ketone group, unless it is acylated (Figure 4A). After treatment with DDQ, all of the $\mathrm{C}_{6}-\mathrm{NBD}$-sphingosine was converted into corresponding 3-oxoforms, which have a higher TLC mobility, as described previously [25] (Figure 4C, lanes 1 and 2). The same was true for acyl- $\mathrm{C}_{6}-$ NBD-sphingosine (Figure 4C, lanes 3 and 4). Controls showed that $\mathrm{C}_{6}-\mathrm{NBD}-\mathrm{DHS}$ and acyl-C ${ }_{6}-\mathrm{NBD}-\mathrm{DHS}$ lacking the $\Delta 4$ double bond were not oxidized (Figures 4D and 4E). These results suggest that the microsomal ceramide esterification by Lro1p involves the hydroxy group on $\mathrm{C} 1$, not $\mathrm{C} 3$, of the LCB.

\section{Lro1p transfers oleic acid on to NBD-ceramide}

If Lrolp is the enzyme that acylates ceramides, we would expect that it transfers on to ceramides the same $\mathrm{C}_{16}$ and $\mathrm{C}_{18}$ fatty acids as to DAG. To test this, microsomes from WT cells were incubated with the ceramide analogue $\mathrm{C}_{6}-$ NBD-DHS. Microsomes were subsequently extracted and analysed by high-resolution FT-MS and structural analysis by ion-trap MS/MS [18,26]. FT-MS analysis detected a molecular ion with $\mathrm{m} / \mathrm{z} 840.6215$ in microsomes incubated with 

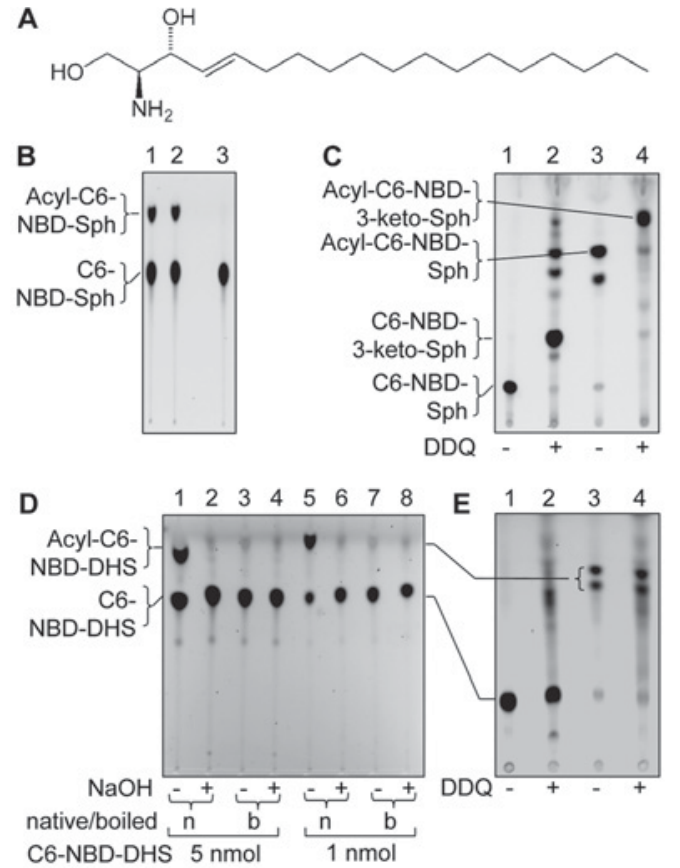

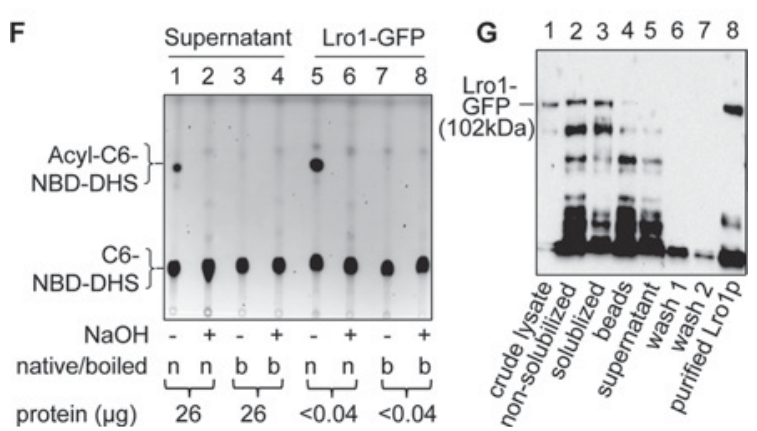

Figure 4 Lro1p acylates the hydroxy group at $\mathrm{C} 1$ of ceramides

(A) Formula of D-erythro-sphingosine. (B) The experiment shown in Figure 3(C), lane 5 was repeated using $\mathrm{C}_{6}-\mathrm{NBD}-$ sphingosine as a substrate instead of $\mathrm{C}_{6}-\mathrm{NBD}-\mathrm{DHS}$ (lanes 1 and 2). Lane 3 contains the $\mathrm{C}_{6}-\mathrm{NBD}$-sphingosine as obtained from Invitrogen. Lipids were extracted and resolved by TLC. (C) Acyl- $\mathrm{C}_{6}-\mathrm{NBD}$-sphingosine and $\mathrm{C}_{6}-\mathrm{NBD}-$ sphingosine from (B) were scraped off of the plate. Lipids were extracted from the silica and incubated for $48 \mathrm{~h}$ at $37^{\circ} \mathrm{C}$ with or without $3 \% \mathrm{DDQ}$ in $40 \mu \mathrm{l}$ of dioxane and then dried in a rotary evaporator as described previously [25]. The lipids were resuspended in $3 \mathrm{ml}$ of chloroform/methanol [2:1 (v/v)] and $0.6 \mathrm{ml}$ of $0.1 \mathrm{M}$ sodium hydroxide was added. After vigorous shaking and brief centrifugation the lower layer (organic phase) was recovered and re-extracted twice with $2 \mathrm{ml}$ of methanol/0.1 M sodium hydroxide [1:1 (v/v)] and twice more with $2 \mathrm{ml}$ of methanol/water [1:1 (v/v)]. The lipids were resolved by TLC in chloroform/methanol/glacial acetic acid (90:1:9, by vol.) and then visualized by direct fluorescence using a FluorChem fluorescence detector. Oxidation of the C3 hydroxy group increases the mobility in this solvent system [25]. (D) The same experiment as in (B) was performed using 5 or $1 \mathrm{nmol}$ of $\mathrm{C}_{6}-\mathrm{NBD}-\mathrm{DHS}$ as a substrate. (E) Acyl- $\mathrm{C}_{6}-\mathrm{NBD}-\mathrm{DHS}$ and $\mathrm{C}_{6}-\mathrm{NBD}-\mathrm{DHS}$ of $(\mathbf{D})$ were scraped and processed as in (C). (F) Lro1p-GFP was purified using an anti-GFP antibody. Equivalent aliquots of purified Lro1p-GFP bound to affinity beads (lanes 5-8) or of supernatant containing non-bound microsomal proteins were incubated with $\mathrm{C}_{6}-\mathrm{NBD}-\mathrm{DHS}$ and $\mathrm{PC}$ for $2 \mathrm{~h}$ at room temperature. Lipids were extracted and separated on TLC as in (C). (G) Aliquots corresponding to equivalent amounts of starting material taken throughout purification were analysed by Western blotting using an anti-GFP antibody. b, boiled; n, native; Sph, sphingosine.

$\mathrm{C}_{6}-\mathrm{NBD}-\mathrm{DHS}$, but not in microsomes without the addition of $\mathrm{C}_{6}-\mathrm{NBD}-\mathrm{DHS}$ or if microsomes had been boiled (Figures $5 \mathrm{~A}-$ 5D). With a mass accuracy of 0.6 p.p.m., this molecular ion matches the identity of the acylceramide $\mathrm{C}_{18: 1}-\mathrm{C}_{6}-\mathrm{NBD}-$ DHS (calculated $\mathrm{m} / \mathrm{z} 840.6220$ ). To confirm the identity of the $\mathrm{C}_{18: 1}-\mathrm{C}_{6}-\mathrm{NBD}-\mathrm{DHS}$ species we performed structural analysis by ion-trap MS/MS. The fragment ions derived from the ion with $\mathrm{m} / \mathrm{z} 840.6215$ could all be ascribed structural features in the intact acylceramide ion (Supplementary Figure S2 at http://www.BiochemJ.org/bj/447/bj4470103add.htm). Fragmentation thus confirms the synthesis of $\mathrm{C}_{18: 1}-\mathrm{C}_{6}-\mathrm{NBD}-\mathrm{DHS}$ in WT microsomes incubated with the precursor $\mathrm{C}_{6}-\mathrm{NBD}-\mathrm{DHS}$.

Next, to confirm that Lrolp is responsible for the synthesis of $\mathrm{C}_{18: 1}-\mathrm{C}_{6}-\mathrm{NBD}-\mathrm{DHS}$, we tested whether increasing the expression level of the enzyme would increase the production of the acylceramide species. To this end, we monitored the production of $\mathrm{C}_{18: 1}-\mathrm{C}_{6}-\mathrm{NBD}-\mathrm{DHS}$ in microsomes from arel $\triangle$ are $2 \triangle$ dgal $\triangle . L R O 1$ cells overexpressing LRO1 when cultured on galactose and in microsomes from low-levelexpressing cells cultured on glucose. We observed that the levels of $\mathrm{C}_{18: 1}-\mathrm{C}_{6}-\mathrm{NBD}-\mathrm{DHS}$ were massively increased when Lrolp was overexpressed (Figures 5E-5G). In comparison, incubating microsomes from cells overexpressing $D G A 1$ with $\mathrm{C}_{6}-\mathrm{NBD}-$ DHS did not yield significant amounts of $\mathrm{C}_{18: 1}-\mathrm{C}_{6}-\mathrm{NBD}-\mathrm{DHS}$ (Figure 5H).

$\mathrm{PE}$ and $\mathrm{PC}$, which are the preferred substrates of Lro1p, most often carry $\mathrm{C}_{18: 1}$ at their $s n-2$ position [27] and, as shown in Figure 5, this species seems to be attached by microsomes in an LRO1-dependent manner to $\mathrm{C}_{6}-\mathrm{NBD}-\mathrm{DHS}$. Taken together, these data support the idea that Lrolp is directly involved in transferring the fatty acid from PE or PC to ceramides.

\section{Purified Lro1p can acylate NBD-ceramide in vitro}

Lrolp-GFP was immunopurified from a strain with the chromosomal $L R O 1$ tagged with GFP and placed under the GAL1 promoter (Figure 4G). Purified Lro1p-GFP was assayed in the presence of NBD-ceramide and PC as shown in Figure 4(F). Calculating how much NBD-ceramide was transformed into acylceramide per microgram of protein during the assay demonstrated that the ceramide acylating activity was more than 800-fold enriched in the purified Lro1p-GFP fraction as compared with the immunodepleted supernatant. This again strongly suggests that the ceramide acylation reaction is carried out by Lro1p.

\section{Ceramide acylation also occurs in living cells}

Many processes taking place in vitro have no physiological correlate. Our calculations on the basis of concentrations of free ceramides in cells reported in the literature $[4,28]$ and on the specific activity of $\left[{ }^{3} \mathrm{H}\right]$ palmitate added to microsomes of WT cells in assays of the type shown in Figure 2(A) led us to conclude that we generated approximately $45-125 \mathrm{pmol}$ of $\left[{ }^{3} \mathrm{H}\right] \mathrm{C}_{16}$-ceramide in microsomes that already contained a minimum of 50-100 pmol of $\mathrm{C}_{26}$-ceramides. This latter estimate is probably too low, since it can be expected that ceramides are more concentrated in ERderived Lro1p-containing microsomes than in the average cellular membrane. Also, when doing reverse ceramidase assays with WT.YPC1 microsomes as in Figure 2(A), but not adding nonradioactive palmitate into the assays, so that only $14 \mathrm{pmol}$ of $\left[{ }^{3} \mathrm{H}\right]$ ceramide was generated, we always found that $25-30 \%$ of ceramides appeared as acylceramides (results not shown). This convinced us that the acylation of $\left[{ }^{3} \mathrm{H}\right] \mathrm{C}_{16}$-ceramide by microsomes observed in vitro (Figure $1 \mathrm{~A}$ ) occurred at ceramide concentrations that were not significantly above the physiological range of ceramides in living cells. To gain further insight and to see also whether $\mathrm{C}_{26}$-ceramides were acylated, we labelled yeast cells with $\left[{ }^{14} \mathrm{C}\right]$ serine, allowing us to follow sphingolipid metabolism in vivo. WT cells fed with $\left[{ }^{14} \mathrm{C}\right]$ serine produced a substantial amount of a non-polar lipid migrating to the position 


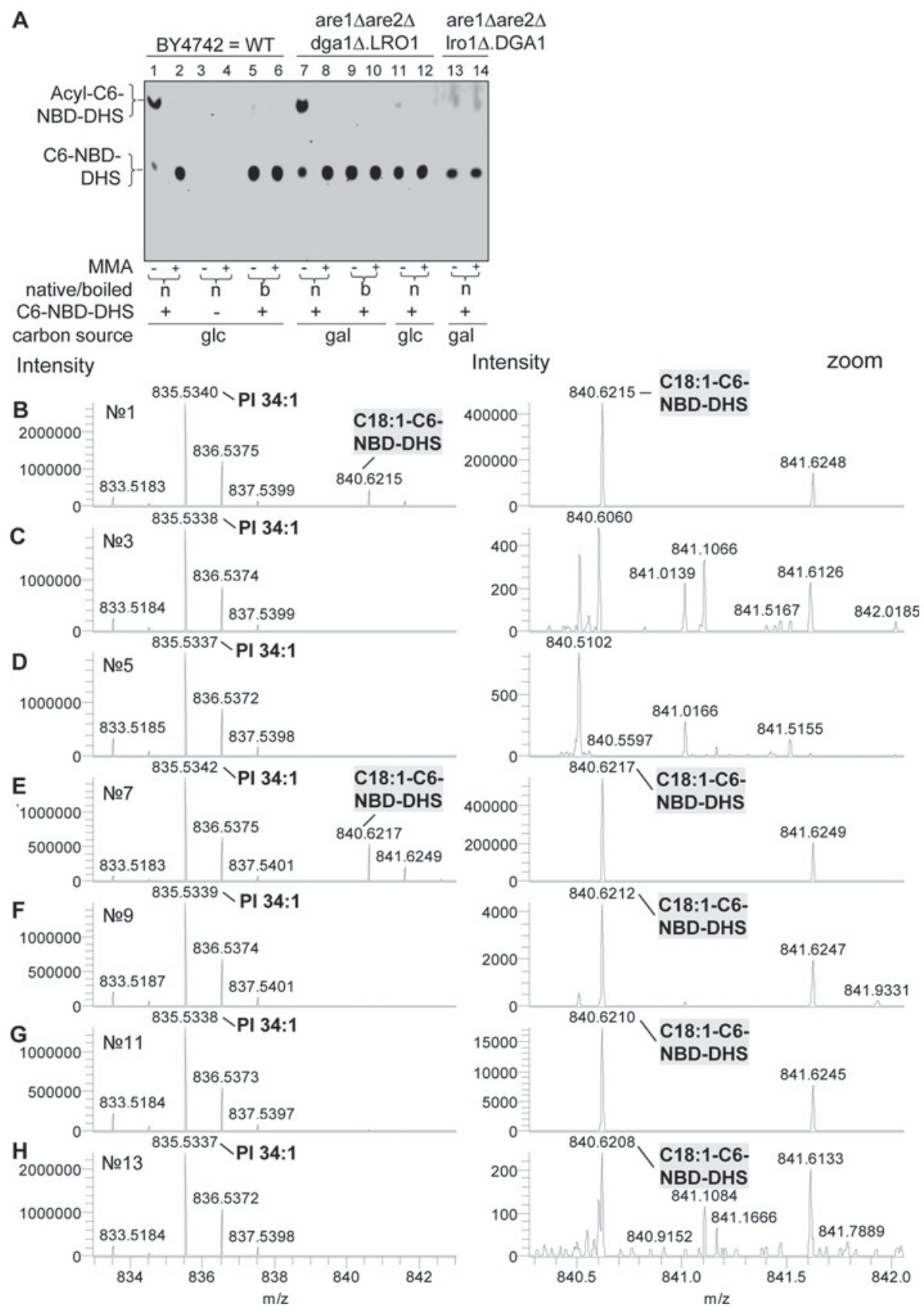

Figure 5 Profiling of $\mathrm{C}_{18: 1}-\mathrm{C}_{6}-\mathrm{NBD}-\mathrm{DHS}$ by MS

(A) The indicated strains were grown on glucose or galactose overnight. Native or boiled microsomes from WT and mutants were incubated for $2 \mathrm{~h}$ at $30^{\circ} \mathrm{C}$ in the presence or absence of $\mathrm{C}_{6}-\mathrm{NBD}-\mathrm{DHS}$. Each reaction was split into two equal parts of $20 \mu \mathrm{l}$, each containing $25 \mu \mathrm{g}$ of protein. Lipids extracted from one half were split and treated with methanol or MMA for alkaline hydrolysis and analysed by TLC. b, boiled; gal, galactose; glc, glucose; n, native. (B-H) Lipid extracts of the second half of the microsomes were subjected to FT-MS analysis as described in the Experimental section. Panels on the right-hand side depict magnified spectra of those on the left-hand side. (B-H) contain samples corresponding to lanes 1, 3, 5, 7, 9, 11 and 13 of (A) as indicated. (B) Microsomes from WT cells incubated with $\mathrm{C}_{6}-\mathrm{NBD}-\mathrm{DHS}$; (C) microsomes from WT cells without the addition of $\mathrm{C}_{6}-\mathrm{NBD}-\mathrm{DHS}$; (D) microsomes from WT cells, boiled and incubated with $\mathrm{C}_{6}-\mathrm{NBD}-\mathrm{DHS}$; (E) microsomes from are1 $\Delta$ are2 $\Delta$ dga1 $\Delta$. LR01 cells cultured in YPG incubated with $\mathrm{C}_{6}-\mathrm{NBD}-\mathrm{DHS}$; (F) microsomes from are1 $\Delta$ are2 $\Delta d g a 1 \Delta . L R 01$ cells cultured in YPG, boiled and incubated with $\mathrm{C}_{6}-\mathrm{NBD}-\mathrm{DHS} ;(\mathbf{G})$ microsomes from are1 $\Delta$ are2 $\Delta$ dga1 $\Delta$. LR01 cells cultured in YPD incubated with $\mathrm{C}_{6}-\mathrm{NBD}-\mathrm{DHS}$; and $(\mathbf{H})$ microsomes from are1 $\Delta$ are2 $\Delta /$ ro1 $\Delta$.DGA1 cells cultured with YPG incubated with $\mathrm{C}_{6}-\mathrm{NBD}-\mathrm{DHS}$.

of acylated ceramide (Figure 6A, asterisk). Mild base treatment led to the disappearance of part of this lipid and the appearance or increases of lipids considered to represent DHS- $\mathrm{C}_{26}$ and PHS$\mathrm{C}_{26}-\mathrm{OH}$ (Figure 6A, lanes 7 and 8). In many cases hydrolysis of these presumably acylated ceramides was incomplete, in others it was complete and we presently are not quite sure whether this hydrophobic lipid is heterogeneous, containing a mild-base- sensitive and a mild-base-resistant component, or if it is not efficiently solubilized and therefore not efficiently hydrolysed.

As shown in Figure 6(A), we labelled the living cells with $\left[{ }^{14} \mathrm{C}\right]$ serine for various periods of time allowing us to observe the kinetics of acylceramide synthesis (Figure 6A). The level of $\left[{ }^{14} \mathrm{C}\right]$ ceramides reached steady-state levels after $40 \mathrm{~min}$ and thereafter slowly declined (Figure 6B). Acylceramides increased 
A

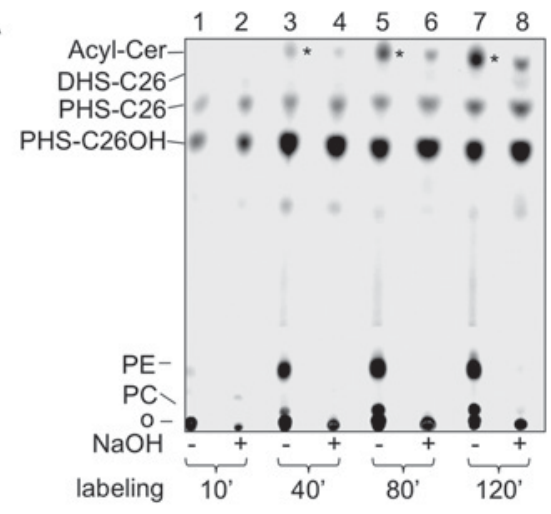

C

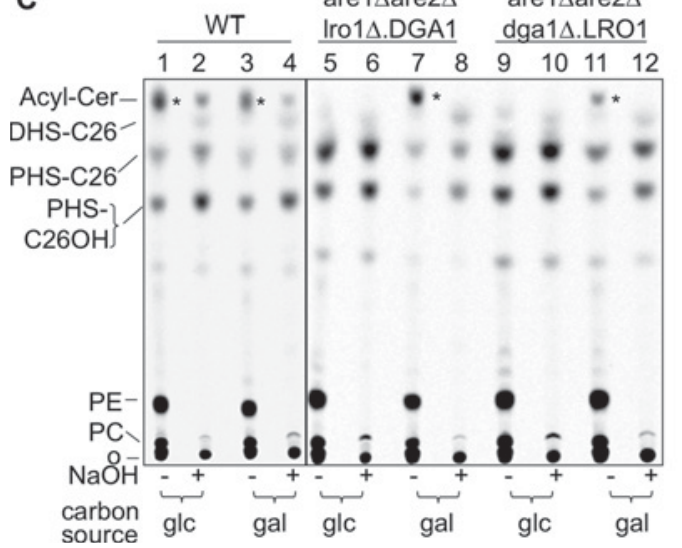

B
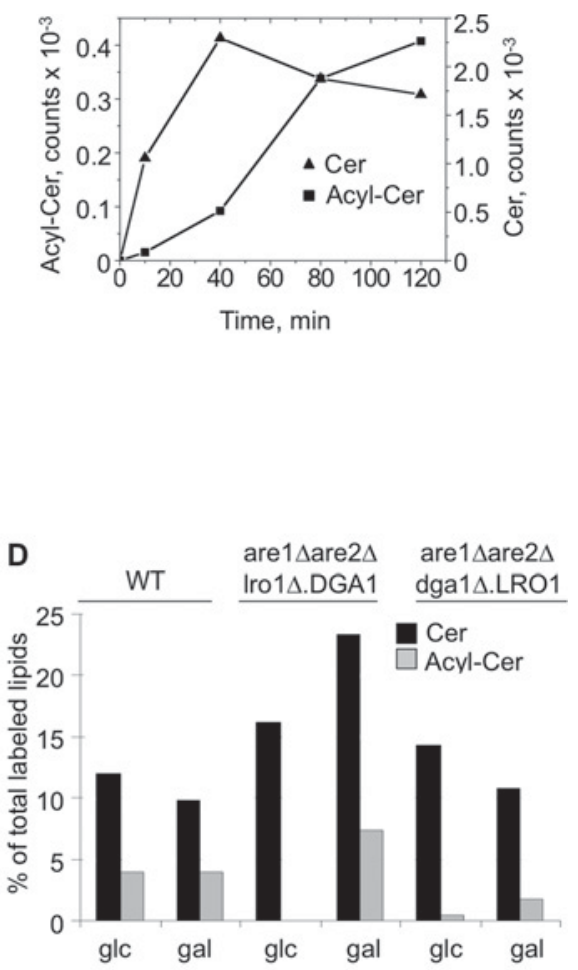

\section{Figure 6 DGA1 and LR01 make acylceramides in vivo}

(A) WT cells were metabolically labelled with $\left[{ }^{14} \mathrm{C}\right]$ serine for 10-120 min. Lipids were extracted, treated with sodium hydroxide or mock-incubated and separated by TLC; 0, origin. The assignment of $\mathrm{DHS}_{-} \mathrm{C}_{26}, \mathrm{PHS}_{-} \mathrm{C}_{26}$ and PHS- $\mathrm{C}_{26}-\mathrm{OH}$ to distinct bands in this and following Figures is tentative and solely based on the presence or absence of major bands of the same mobility in sur2 $\Delta$, scs7 $\Delta$ and sur2 $\Delta$ SCS7 $\Delta$ cells lacking the LCB- $C_{4}$-hydroxylase, the fatty acid $\mathrm{C}_{2}$-hydroxylase or both [31] (results not shown). Assignments are supported by previous data on the relative abundance of the various IPC and ceramide species in yeast [18,30,32]. The TLC system used is mainly sensitive to the number of hydroxy groups of ceramides, not fatty acid chain length. (B) Amounts of acylceramides and the sum of all ceramides from $(\mathbf{A})$ were obtained by radioscanning and plotted as c.p.m. against time of labelling. (C) WT, are1 $\Delta$ are2 $\Delta / r 01 \Delta$.DGA1 and are1 $\Delta$ are2 $\Delta$ dga1 $\Delta$. LR01 cells were grown overnight on glucose (glc) or galactose (gal) and then labelled with $\left[{ }^{14} \mathrm{C}\right]$ serine at $30^{\circ} \mathrm{C}$ for 160 min on the same carbon source as used in the preculture. Growth on galactose led to a drastic induction of Lro1p and Dga1p (Supplementary Figure S3 at http://www.BiochemJ.org/bj/447/bj4470103add.htm). Lipids were extracted, desalted and deacylated with sodium hydroxide or were mock-incubated. They then were resolved by TLC. (D) Ceramides and acylceramides in (C) were quantified by radioscanning. Cer, ceramide; gal, galactose; glc, glucose; 0 , origin.

at maximal speed only after 40 min, when ceramides had reached their maximal level but did not reach a plateau during the $2 \mathrm{~h}$ of labelling (Figure 6B). These data are compatible with a continuous acylation of part of the newly made ceramides. The same amounts of acylceramide were also observed, when ypcl $\Delta y d c 1 \Delta$ cells were metabolically labelled, suggesting that the bulk of ceramides that are acylated in vivo are made by Lag1p and Lac1p (results not shown).

To see whether Lro1p, and possibly Dgalp or Are $2 p$, were involved in making the very hydrophobic lipid species observed in Figure 6(A), we again used the are $1 \triangle$ are $2 \triangle$ lrol $\triangle . D G A 1$, are $1 \triangle$ are $2 \Delta$ dgal $\triangle . L R O 1$ and are $1 \Delta$ lrol $\triangle$ dgal $\triangle . A R E 2$ strains, in which the endogenous DGA1, LRO1 or ARE2 genes have been placed behind the GAL1-promoter respectively. These mutants have no LDs when grown on glucose, but induce LDs on galactose, indicating that expression of one of the three genes LRO1, DGA1 or ARE2 is sufficient to cause the appearance of LDs [12,16]. Accordingly, these strains were grown on glucose or on galactose and then labelled with $\left[{ }^{14} \mathrm{C}\right]$ serine along with WT cells (Figure 6C). LROI and DGAl overexpression was verified by Western blotting (Supplementary Figure S3 at http://www.BiochemJ.org/bj/447/bj4470103add.htm) and allowed the cells to produce significant amounts of acylceramides
(Figure 6C, lanes 5-12, and Figure 6D). ARE2 overexpression did not have any effect on the conversion of ceramide into its esters (results not shown), although its overexpression leads to a rapid appearance of LDs in an are $1 \Delta$ are $2 \Delta \operatorname{lrol} \Delta d g a 1 \Delta$ background [29].

Significantly, all of these cell lines growing on glucose made very few acylceramides. This indicates that Lrolp and Dgalp are the only enzymes that can acylate the ceramide in living cells.

The quantification of the presumed acylceramides was always done by subtracting mild-base-resistant counts from total counts in the acylceramide band of the untreated sample (see the Experimental section). Calculated in this way, $7 \%$ of the total incorporated radioactivity was present as acylceramide when $D G A 1$ was overexpressed, and only $2 \%$ when $L R O 1$ was overexpressed (Figure 6D). In WT cells acylceramides amounted usually to approximately $2-5 \%$ of total labelled lipids. In other words, a quarter of the total ceramides was usually esterified in WT cells (Figure 6D).

\section{Characterization of $\left[{ }^{14} \mathrm{C}\right]$ serine-labelled acylceramides}

To obtain additional evidence for the biosynthesis of acylceramide in vivo we also labelled cells with $\left[{ }^{14} \mathrm{C}\right]$ serine in the presence of 


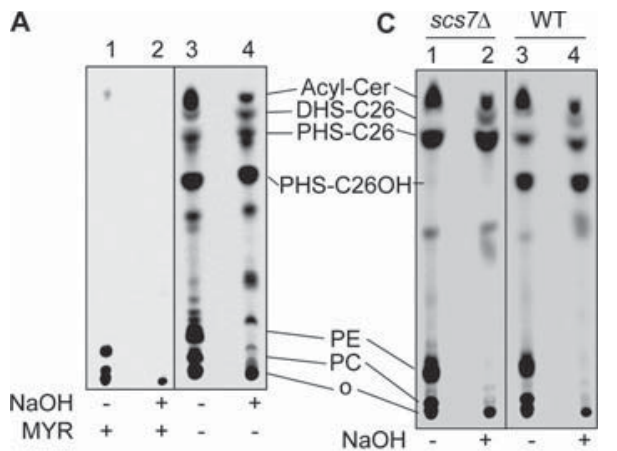

B

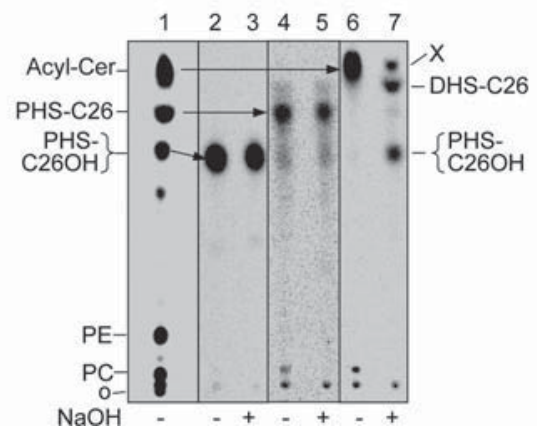

Figure 7 The main ceramides acylated in WT cells in vivo co-migrate with DHS- $\mathrm{C}_{26}$ and PHS $-\mathrm{C}_{26}-\mathrm{OH}$

(A) WT cells were cultured with or without $40 \mu \mathrm{g} / \mathrm{ml}$ myriocin (MYR) for $2 \mathrm{~h}$. Then the cells were labelled with $\left[{ }^{14} \mathrm{C}\right]$ serine for $160 \mathrm{~min}$ at $30^{\circ} \mathrm{C}$ in the same medium as used for pre-incubation. The extracted lipids were treated and resolved by TLC. (B) WT cells were grown at $30^{\circ} \mathrm{C}$ and labelled with $\left[{ }^{14} \mathrm{C}\right]$ serine for $2 \mathrm{~h}$ at the same temperature. The labelled lipids were resolved by TLC resulting in the profile in lane 1. The main ceramides and acylceramides were scraped off of the TLC plate, extracted from the silica and subjected to mild base hydrolysis with sodium hydroxide or mock-treated. Horizontal arrows connect identical lipids before and after scraping. The sodium-hydroxide-resistant lipid co-migrating with acylceramide is marked as ' $X$ '. The Figure shows one of three experiments which gave similar results. The quantification of all three experiments is given in Table 3. (C) $\operatorname{scs} 7 \Delta$ and WT cells were labelled with $\left[{ }^{14} \mathrm{C}\right]$ serine and lipid extracts were analysed by TLC. Cer, ceramide; 0, origin.

myriocin, a specific inhibitor of the serine palmitoyl transferase catalysing the first step of sphingolipid biosynthesis. The synthesis of ceramides and acylceramide was strongly repressed by myriocin (Figure 7A). This further confirmed that the very hydrophobic labelled lipids observed after metabolic labelling with $\left[{ }^{14} \mathrm{C}\right]$ serine are indeed derived from sphingolipids, the biosynthesis of which requires $L C B 1$. A similar reduction of ceramide and acylceramide biosynthesis was also observed in the thermosensitive lcb1-100 cells, labelled at $37^{\circ} \mathrm{C}$ (results not shown).

Yeast ceramides either contain DHS or PHS, and their fatty acid can be either non-, mono- or bis-hydroxylated [30,31]. The most abundant ceramide of yeast is phytoceramide containing an $\alpha$-hydroxylated $\mathrm{C}_{26: 0}$ fatty acid (PHS- $\left.\mathrm{C}_{26}-\mathrm{OH}\right)[18,32]$. To find out what ceramides became acylated, and to corroborate the idea that the most hydrophobic $\left[{ }^{14} \mathrm{C}\right]$ serine-labelled lipids in Figure 6 are acylceramides, such lipids were scraped off of the TLC plate and treated with mild base. Acylceramide from WT cells contained on average $40 \%$ of a lipid running with PHS- $\mathrm{C}_{26}-\mathrm{OH}$ and $30 \%$ of a lipid running with DHS- $\mathrm{C}_{26}$, the remainder being mild base resistant for unknown reasons (see above) (Figure 7B and Table 3). To see whether PHS- $\mathrm{C}_{26}$-type ceramides can also be acylated, we also labelled the $\operatorname{scs} 7 \Delta$ strain, lacking the fatty acid hydroxylase [31] (Figure 7C). Metabolic labelling of $\operatorname{scs} 7 \Delta$ with $\left[{ }^{14} \mathrm{C}\right]$ serine yielded a major band in the region of acylceramides,
Table 3 Quantification of deacylation products of $\left[{ }^{14} \mathrm{C}\right]$ serine-labelled acylceramides

The abundance of different lipids in lane 7 of Figure 7(B) and in two similar experiments is expressed as a percentage of total lipids after mild base treatment.

\begin{tabular}{lllll}
\hline & \multicolumn{5}{c}{ Experiment number } \\
\cline { 2 - 5 } Deacetylation product & 1 & 2 & 3 & $1-3$ mean (S.D.) \\
\hline X (sodium-hydroxide-resistant) & $23.1 \%$ & $38.9 \%$ & $27.7 \%$ & $29.9 \%(8.1)$ \\
DHS- $\mathrm{C}_{26}$ & $37.9 \%$ & $37.9 \%$ & $15.4 \%$ & $30.4 \%(13.0)$ \\
PHS- $\mathrm{C}_{26}-\mathrm{OH}$ & $38.9 \%$ & $23.3 \%$ & $56.9 \%$ & $39.7 \%(16.8)$ \\
& & & & \\
\hline
\end{tabular}

a large fraction of which was hydrolysed to lipids running with DHS- $\mathrm{C}_{26}$ and PHS- $\mathrm{C}_{26}$, the latter being the main ceramide of this strain [31]. Thus the deletion of SCS7 does not prevent the biosynthesis of acylceramides and suggests that, although PHS$\mathrm{C}_{26}$ is not efficiently acylated in WT cells, the acyltransferases can utilize it in a $\operatorname{scs} 7 \Delta$ background and that the resulting acylated PHS- $\mathrm{C}_{26}$ is stable.

In view of the variability of the relative amounts of acylceramides observed in our experiments and in view of the known ability of yeast cells to secrete apolar lipids, such as acetylated cholesterol [33], we tested whether yeast cells would secrete any acylceramide. However, when analysing the growth medium we could not detect any secreted acylceramides (Supplementary Figure S4A at http://www.BiochemJ.org/bj/447/ bj4470103add.htm).

\section{Acylceramides can be mobilized when fatty acid synthesis is compromised}

We also wondered whether an increased demand for fatty acids inducing the disappearance of LDs could lead to the hydrolysis of acylceramides. To test for this we utilized conditions in which high amounts of acylceramide were available for degradation. DGAI and LROI were simultaneously induced in are $1 \triangle$ are $2 \triangle$ lrol $\triangle . D G A 1 . L R O 1$ cells in galactose-containing medium and cells were at the same time labelled with $\left[{ }^{14} \mathrm{C}\right]$ serine for $16 \mathrm{~h}$ (Figure 8A). Chasing in fresh glucose medium, allowing for repression of DGAI and $L R O 1$, did not result in mobilization of acylceramides as compared with the simple continuation of the culture in the labelling medium (Figure 8A, condition 2 compared with condition 1, and Figure 8B). On the other hand, chasing with glucose medium supplemented with the fatty acid synthase inhibitor cerulenin led to the almost complete disappearance of acylceramides within $6 \mathrm{~h}$ (Figure 8A, condition 3, and Figure 8B). It is worth noting that, in Figure 8, acylceramides were labelled in the absence of cycloheximide. Indeed, this drug enhances incorporation of $\left[{ }^{14} \mathrm{C}\right]$ serine into lipids, but acylceramides are also made in its absence (Supplementary Figure S4B).

We also tried to force the mobilization of acylceramides by inflicting a want of sphingolipids. For this, cells were labelled with $\left[{ }^{14} \mathrm{C}\right]$ serine for $12 \mathrm{~h}$ and chased for the indicated periods with non-radioactive serine in the presence of myriocin (Figure 8C). WT cells were used in this experiment as well as a strain deficient in Isc1p, the only enzyme in yeast able to hydrolyse IPCs $[34,35]$. In iscl $\Delta$ mutants the pathway generating ceramides via the breakdown of complex sphingolipids is blocked (Figure 1). TLC analysis did not show any significant mobilization of acylceramide during chase in both WT and isc $1 \Delta$ (Figure 8C) cells, and the quantification by Berthold scanning confirmed this impression (Supplementary Figrues S5A and S5B at http://www.BiochemJ.org/bj/447/bj4470103add.htm, red 

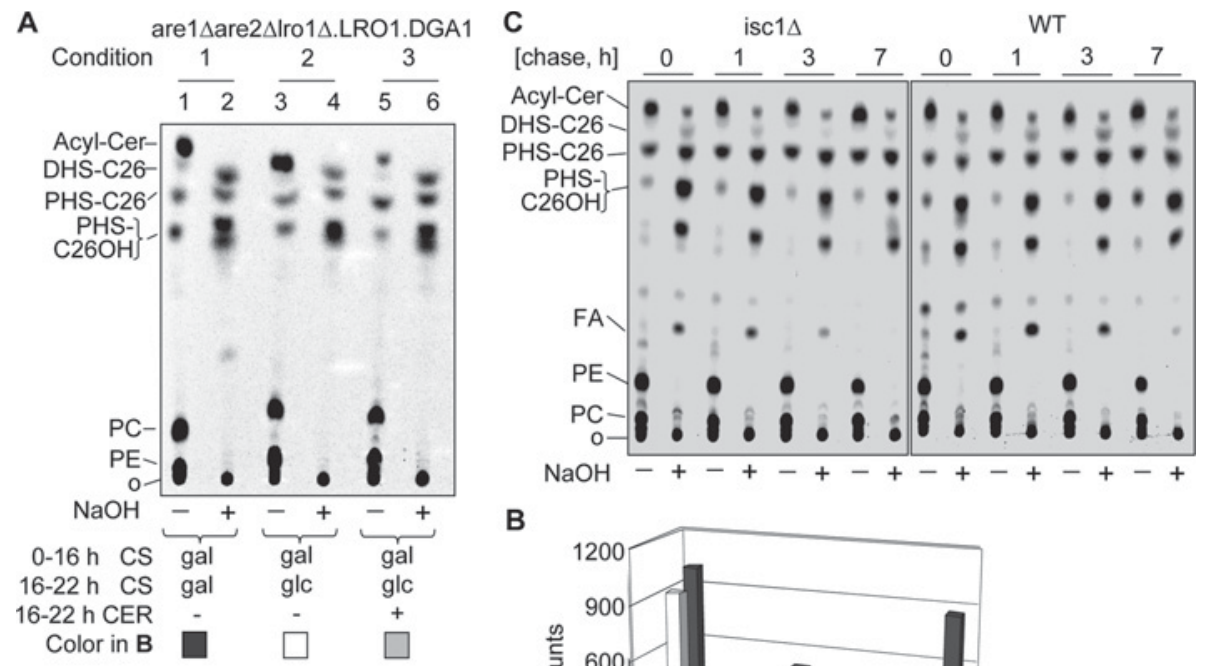

B

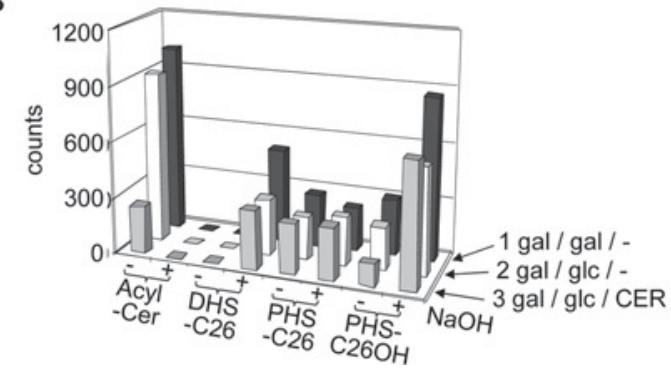

Figure 8 Disappearance of acylceramides under drug-induced lipid deprivation

(A) are1 $\Delta$ are2 $\triangle$ dga1 $\triangle . D G A 1$ cells bearing DGA1 behind the GAL1 promoter were grown overnight to a $D_{600}$ of 3.0 in galactose medium while being labelled with $\left[{ }^{14} \mathrm{C}\right]$ serine at $30^{\circ} \mathrm{C}(16 \mathrm{~h}$ labelling). On the next day, the cell culture was split into three equal parts and treated as follows. Condition 1 , culture of cells in the presence of [ $\left.{ }^{14} \mathrm{C}\right]$ serine was simply continued for a further $6 \mathrm{~h}$ without changing the medium; condition 2, cells were collected, washed and further incubated in an equal volume of fresh medium without $\left[{ }^{14} \mathrm{C}\right]$ serine containing glucose as a carbon source (CS) for $6 \mathrm{~h}$; condition 3, as for condition 2, but the medium was supplemented with $10 \mu \mathrm{g} / \mathrm{ml}$ cerulenin (CER). Extracted lipids were resolved by TLC. (B) Quantification of data in (A) was expressed as absolute counts present in the various lipid species on the Berthold scan. (C) WT and isc1 $\Delta$ cells were labelled with $\left[{ }^{14} \mathrm{C}\right]$ serine for $12 \mathrm{~h}$ at $30^{\circ} \mathrm{C}$ to a $\mathrm{D}_{600}$ of 8.0 . After labelling, cells were collected, washed and resuspended at a $D_{600}$ of 1.0 in YPD medium supplemented with $7 \mathrm{mg} / \mathrm{ml}$ serine and $40 \mu \mathrm{g} / \mathrm{ml}$ myriocin. Cells were chased at $30^{\circ} \mathrm{C}$ and a fixed volume of culture was removed for lipid analysis after 0,1,3 or $7 \mathrm{~h}$. Lipids were extracted and treated as described above. Quantification of some lipid species during chase are shown in Supplementary Figure S5 (at http://www.BiochemJ.org/bj/447/bj4470103add.htm). Cer, ceramide; gal, galactose; glc, glucose; 0, origin.

columns). Indeed, the lipid profiles in WT and iscl $\Delta$ cells were very similar. Thus it appears that an acute lack of sphingolipids does not induce a mobilization of the ceramide moiety of acylceramides.

\section{DISCUSSION}

This present paper discusses the existence of a metabolic pathway in yeast, which previously had been characterized in mammalian cells. It allows ceramides to not only be processed for IPC biosynthesis or degradation via the ceramidases, but also to be transformed into acylceramides as shown in Figure 1. Acylceramides, as judged by their physicochemical properties, could well be deposited in LDs, although this will have to be tested experimentally. At the moment it is not clear whether this pathway represents a mere detoxicification mechanism to protect cells from toxic amounts of ceramides or fatty acids [36], or whether it also serves a storage purpose, similar to TAGs, which are mobilized to allow for rapid membrane biosynthesis when stationary phase cells are diluted into nutrient-rich media and resume growth [37].

The acylceramides seem to be made by Lrolp and Dgalp, the former being the only enzyme showing activity in our microsomal in vitro system. In intact cells Dgalp also seems to be able to acylate ceramides, according to metabolic labelling experiments. It thus appears that Dgalp and Lrolp can utilize ceramide instead of DAG, but it is difficult to estimate the relative contributions of these enzymes from our experiments, because the demonstration that either enzyme can acylate ceramides in living cells was performed in cells overexpressing either Lro1p or Dga1p (Figure 6C).

Dgalp and Lrolp were previously shown to have relaxed substrate specificity in that they can also use monoacylglycerol and long-chain alcohols as an acceptor substrate [38,39], although they cannot use ergosterol [16,40]. It has been reported that in microsomal assays Lrolp uses PE and PC as donor substrates, transfers saturated, unsaturated and even the nonnatural polyunsaturated fatty acids groups and may transfer fatty acids also from the $s n-1$ position, albeit at an approximately 10fold lower rate than from the $s n-2$ position; it can even use DAG as a donor substrate [15,38].

We were able to show that microsomes attach O-acyls to the position 1 of sphingosine-containing ceramides using DDQ oxidation (Figure 4). We tried to confirm this result by testing whether ceramides lacking the hydroxy group on $\mathrm{C} 1$ or lacking the hydroxylated $\mathrm{C} 1$ atom altogether could still be acylated. For this we added to microsomes $\left[{ }^{3} \mathrm{H}\right] \mathrm{C}_{16: 0}$ plus 1-deoxysphinganine or 1-deoxymethylsphingosine, lacking the terminal $\mathrm{OH}$ - or $\mathrm{OH}$ $\mathrm{CH}_{2}$ - group of classical LCBs, but these LCB analogues were not recognized as substrates by Ypc1p, and no corresponding 1-deoxy- or 1-deoxymethyl- $\left[{ }^{3} \mathrm{H}\right]$ ceramides were generated in our microsomal in vitro system (results not shown). Ypc1p also did not recognize 3-oxo-sphinganine (results not shown). Thus we could not confirm that the O-acylation of DHS- and PHS-containing ceramides occurs on $\mathrm{C} 1$ using these approaches.

In our TLC system the deacylation products of the invivo-generated acylceramides mainly ran at the positions of 
DHS- $\mathrm{C}_{26}$ and PHS- $\mathrm{C}_{26}-\mathrm{OH}$, whereas almost no material comigrating with $\mathrm{PHS}-\mathrm{C}_{26}-\mathrm{OH}$ appeared upon deacylation of acylceramides of the $\operatorname{scs} 7 \Delta$ mutant lacking fatty acid hydroxylase (Figure 7C). Although this suggests that Dga1p and Lro1p mainly acylate DHS- $\mathrm{C}_{26}$ and $\mathrm{PHS}-\mathrm{C}_{26}-\mathrm{OH}$, other ceramides may run to the same position on TLC. For instance, the position in this TLC system of the previously described PHS- $\mathrm{C}_{14}-\mathrm{OH}$ species [32] is unknown. Clearly more studies are required to identify the exact nature of the ceramide species acylated in living cells.

Lrolp is the only yeast homologue of the mammalian LPLA2, the first and only other enzyme reported to acylate ceramides on $\mathrm{C} 1[23,25,41]$. The enzyme is a group $\mathrm{XV}$ $\mathrm{PLA}_{2}$, and is a close homologue of the extracellular LCAT of high-density lipoproteins. Although LPLA2 seems to function predominantly as a lysosomal acid phospholipase, it can, as many phospholipases, also act as a transacylase in the presence of suitable acceptor substrates. As (donor) substrates it prefers PE and PC and, contrary to its name, can release fatty acids from both $s n-2$ and $s n-1$ positions [42]. The acceptor specificity of LPLA2 is broad, and many long-chain hydrocarbons possessing a primary alcoholic group can be used as substrates [23]. As far as ceramides are concerned, the best substrate in in vitro reactions was $N$-acetyl-sphingosine, and much less activity was found with $N$-octanoyl- or $N$-stearyl-sphingosine as substrates [25]. Whether LPLA2 in vivo uses conventional ceramides with fatty acids of 14-24 carbon atoms is not clear.

Lro1p, LCAT and PLAL2 are homologues and, according to the conserved domains database at NCBI (http://www.ncbi.nlm. nih.gov/cdd/), they all have numerous identities with the 377 residues long pfam02450 consensus sequence over its entire length. Lro1p, LCAT and LPLA2 all contain a catalytic serinehistidine-aspartate triad; the first two in addition also contain a serine lipase motif [VxL(I/V)GHSxG] $[13,43]$. In analogy to LCAT and LPLA2, which are active extracellularly and in the lysosome respectively, the catalytic residues of Lrolp also lie outside the cytoplasm, namely in the ER lumen. Indeed, Lrolp consists of a type II integral membrane glycoprotein with a single transmembrane helix [44]. Ceramides and DAGs therefore need to reach the ER lumen in order to get access to its catalytic site.

Metabolic labelling with $\left[{ }^{14} \mathrm{C}\right]$ serine suggests that some newly made ceramides may be channeled into acylceramide biosynthesis and that they can be remobilized in the presence of cerulenin (Figure 8). It is not clear at present what enzymes hydrolyse the O-acyl group of acylceramides, and also it cannot be decided whether cerulenin mobilizes acylceramides by activating certain hydrolases or whether the mobilization is simply due to the disappearance of LDs [12]. Disappearance of LDs might bring acylceramides into contact with ER-localized hydrolases. Whatever the mechanism, the fact that acylceramides remain stable in the absence of cerulenin but start to disappear in its presence (Figure 8A, lanes 1 and 2 compared with lanes 5 and 6 , and Figure 8B) does suggest that acylceramide breakdown may somehow be regulated.

\section{AUTHOR CONTRIBUTION}

Natalia Voynova and Christine Vionnet carried out most of the experimental work. Christer Ejsing performed and interpreted the mass spectrometric analysis. Natalia Voynova and Andreas Conzelmann designed the experiments and wrote the paper.

\section{ACKNOWLEDGEMENTS}

We thank Roger Schneiter for the communication of unpublished work and for providing us with numerous yeast strains and plasmids. We thank Hans Kristian Hannibal-Bach for extracting microsomes.

\section{FUNDING}

This work was supported by the Swiss National Science Foundation [grant number 31003A 131078/1 (to A.C.)] and the Lundbeckfonden [grant number R45-A4342 (to C.S.E.)] and the Danish Council for Independent Research/Natural Sciences (to C.S.E.).

\section{REFERENCES}

1 Dickson, R. C., Sumanasekera, C. and Lester, R. L. (2006) Functions and metabolism of sphingolipids in Saccharomyces cerevisiae. Prog. Lipid Res. 45, 447-465

2 Levine, T. P., Wiggins, C. A. and Munro, S. (2000) Inositol phosphorylceramide synthase is located in the Golgi apparatus of Saccharomyces cerevisiae. Mol. Biol. Cell 11, 2267-2281

3 Hannun, Y. A. and Obeid, L. M. (2011) Many ceramides. J. Biol. Chem. 286, 27855-27862

4 Guillas, I., Kirchman, P. A., Chuard, R., Pfefferli, M., Jiang, J. C., Jazwinski, S. M. and Conzelmann, A. (2001) C26-CoA-dependent ceramide synthesis of Saccharomyces cerevisiae is operated by Lag1p and Lac1p. EMBO J. 20, 2655-2665

5 Schorling, S., Vallee, B., Barz, W. P., Riezman, H. and Oesterhelt, D. (2001) Lag1p and Lac1p are essential for the Acyl-CoA-dependent ceramide synthase reaction in Saccharomyces cerevisae. Mol. Biol. Cell 12, 3417-3427

6 Mao, C., Xu, R., Bielawska, A. and Obeid, L. M. (2000) Cloning of an alkaline ceramidase from Saccharomyces cerevisiae. An enzyme with reverse (CoA-independent) ceramide synthase activity. J. Biol. Chem. 275, 6876-6884

7 Mao, C., Xu, R., Bielawska, A., Szulc, Z. M. and Obeid, L. M. (2000) Cloning and characterization of a Saccharomyces cerevisiae alkaline ceramidase with specificity for dihydroceramide. J. Biol. Chem. 275, 31369-31378

8 Jiang, J. C., Kirchman, P. A., Allen, M. and Jazwinski, S. M. (2004) Suppressor analysis points to the subtle role of the LAG1 ceramide synthase gene in determining yeast longevity. Exp. Gerontol. 39, 999-1009

9 Cerantola, V., Guillas, I., Roubaty, C., Vionnet, C., Uldry, D., Knudsen, J. and Conzelmann, A. (2009) Aureobasidin A arrests growth of yeast cells through both ceramide intoxication and deprivation of essential inositolphosphorylceramides. Mol Microbiol. 71, 1523-1537

10 Sorger, D. and Daum, G. (2002) Synthesis of triacylglycerols by the acyl-coenzyme A:diacyl-glycerol acyltransferase Dga1p in lipid particles of the yeast Saccharomyces cerevisiae. J. Bacteriol. 184, 519-524

11 Natter, K., Leitner, P., Faschinger, A., Wolinski, H., McCraith, S., Fields, S. and Kohlwein, S. D. (2005) The spatial organization of lipid synthesis in the yeast Saccharomyces cerevisiae derived from large scale green fluorescent protein tagging and high resolution microscopy. Mol. Cell. Proteomics 4, 662-672

12 Jacquier, N., Choudhary, V., Mari, M., Toulmay, A., Reggiori, F. and Schneiter, R. (2011) Lipid droplets are functionally connected to the endoplasmic reticulum in Saccharomyces cerevisiae. J. Cell Sci. 124, 2424-2437

13 Oelkers, P., Tinkelenberg, A., Erdeniz, N., Cromley, D., Billheimer, J. T. and Sturley, S. L. (2000) A lecithin cholesterol acyltransferase-like gene mediates diacylglycerol esterification in yeast. J. Biol. Chem. 275, 15609-15612

14 Oelkers, P., Cromley, D., Padamsee, M., Billheimer, J. T. and Sturley, S. L. (2002) The DGA1 gene determines a second triglyceride synthetic pathway in yeast. J. Biol. Chem. 277, 8877-8881

15 Dahlqvist, A., Stahl, U., Lenman, M., Banas, A., Lee, M., Sandager, L., Ronne, H. and Stymne, S. (2000) Phospholipid:diacylglycerol acyltransferase: an enzyme that catalyzes the acyl-CoA-independent formation of triacylglycerol in yeast and plants. Proc. Natl. Acad. Sci. U.S.A. 97, 6487-6492

16 Sandager, L., Gustavsson, M. H., Stahl, U., Dahlqvist, A., Wiberg, E., Banas, A., Lenman, M., Ronne, H. and Stymne, S. (2002) Storage lipid synthesis is non-essential in yeast. J. Biol. Chem. 277, 6478-6482

17 Kushnirov, V. V. (2000) Rapid and reliable protein extraction from yeast. Yeast $\mathbf{1 6}$ 857-860

18 Ejsing, C. S., Sampaio, J. L., Surendranath, V., Duchoslav, E., Ekroos, K., Klemm, R. W., Simons, K. and Shevchenko, A. (2009) Global analysis of the yeast lipidome by quantitative shotgun mass spectrometry. Proc. Natl. Acad. Sci. U.S.A. 106, 2136-2141

19 Hanson, B. A. and Lester, R. L. (1980) The extraction of inositol-containing phospholipids and phosphatidylcholine from Saccharomyces cerevisiae and Neurospora crassa. J. Lipid Res. 21, 309-315

20 Folch, J., Lees, M. and Stanley, G. H. S. (1957) A simple method for the isolation and purification of total lipides from animal tissues. J. Biol. Chem. 226, 497-509

21 Mao, C., Xu, R., Szulc, Z. M., Bielawska, A., Galadari, S. H. and Obeid, L. M. (2001) Cloning and characterization of a novel human alkaline ceramidase. A mammalian enzyme that hydrolyzes phytoceramide. J. Biol. Chem. 276, 26577-26588 
22 Crawford, J. M., Vinter, D. W. and Gollan, J. L. (1991) Taurocholate induces pericanalicular localization of $\mathrm{C}_{6}$-NBD-ceramide in isolated hepatocyte couplets. Am. J. Physiol. 260, G119-G132

23 Shayman, J. A., Kelly, R., Kollmeyer, J., He, Y. and Abe, A. (2011) Group XV phospholipase A, a lysosomal phospholipase A. Prog. Lipid Res. 50, 1-13

24 Jensen-Pergakes, K., Guo, Z., Giattina, M., Sturley, S. L. and Bard, M. (2001) Transcriptional regulation of the two sterol esterification genes in the yeast Saccharomyces cerevisiae. J. Bacteriol. 183, 4950-4957

25 Abe, A., Shayman, J. A. and Radin. N. S. (1996) A novel enzyme that catalyzes the esterification of $\mathrm{N}$-acetylsphingosine. Metabolism of C2-ceramides. J. Biol. Chem. 271, 14383-14389

26 Ejsing, C. S., Moehring, T., Bahr, U., Duchoslav, E., Karas, M., Simons, K. and Shevchenko, A. (2006) Collision-induced dissociation pathways of yeast sphingolipids and their molecular profiling in total lipid extracts: a study by quadrupole TOF and linear ion trap-orbitrap mass spectrometry. J. Mass Spectrom. 41, 372-389

27 Schneiter, R., Brugger, B., Amann, C. M., Prestwich, G. D., Epand, R. F., Zellnig, G., Wieland, F. T. and Epand, R. M. (2004) Identification and biophysical characterization of a very-long-chain-fatty-acid-substituted phosphatidylinositol in yeast subcellular membranes. Biochem. J. 381, 941-949

28 Han, S., Lone, M. A., Schneiter, R. and Chang, A. (2010) Orm1 and Orm2 are conserved endoplasmic reticulum membrane proteins regulating lipid homeostasis and protein quality control. Proc. Natl. Acad. Sci. U.S.A. 107, 5851-5856

29 Sorger, D., Athenstaedt, K., Hrastnik, C. and Daum, G. (2004) A yeast strain lacking lipid particles bears a defect in ergosterol formation. J. Biol. Chem. 279, 31190-31196

30 Smith, S. W. and Lester, R. L. (1974) Inositol phosphorylceramide, a novel substance and the chief member of a major group of yeast sphingolipids containing a single inositol phosphate. J. Biol. Chem. 249, 3395-3405

31 Haak, D., Gable, K., Beeler, T. and Dunn, T. (1997) Hydroxylation of Saccharomyces cerevisiae ceramides requires Sur2p and Scs7p. J. Biol. Chem. 272, 29704-29710

32 Kitagaki, H., Cowart, L. A., Matmati, N., Vaena de Avalos, S., Novgorodov, S. A., Zeidan, Y. H., Bielawski, J., Obeid, L. M. and Hannun, Y. A. (2007) Isc1 regulates sphingolipid metabolism in yeast mitochondria. Biochim. Biophys. Acta 1768, 2849-2861

33 Tiwari, R., Koffel, R. and Schneiter, R. (2007) An acetylation/deacetylation cycle controls the export of sterols and steroids from S. cerevisiae. EMBO J. 26, 5109-5119

34 Sawai, H., Okamoto, Y., Luberto, C., Mao, C., Bielawska, A., Domae, N. and Hannun, Y. A (2000) Identification of ISC1 (YER019w) as inositol phosphosphingolipid phospholipase C in Saccharomyces cerevisiae. J. Biol. Chem. 275, 39793-39798
35 Betz, C., Zajonc, D., Moll, M. and Schweizer, E. (2002) ISC1-encoded inositol phosphosphingolipid phospholipase $\mathrm{C}$ is involved in $\mathrm{Na}^{+} / \mathrm{Li}^{+}$halotolerance of Saccharomyces cerevisiae. Eur. J. Biochem. 269, 4033-4039

36 Garbarino, J., Padamsee, M., Wilcox, L., Oelkers, P. M., D’Ambrosio, D., Ruggles, K. V. Ramsey, N., Jabado, O., Turkish, A. and Sturley, S. L. (2009) Sterol and diacylglycerol acyltransferase deficiency triggers fatty acid-mediated cell death. J. Biol. Chem. 284 30994-31005

37 Kurat, C. F., Natter, K., Petschnigg, J., Wolinski, H., Scheuringer, K., Scholz, H., Zimmermann, R., Leber, R., Zechner, R. and Kohlwein, S. D. (2006) Obese yeast: triglyceride lipolysis is functionally conserved from mammals to yeast. J. Biol. Chem. 281, 491-500

38 Ghosal, A., Banas, A., Stahl, U., Dahlqvist, A., Lindqvist, Y. and Stymne, S. (2007) Saccharomyces cerevisiae phospholipid:diacylglycerol acyl transferase (PDAT) devoid of its membrane anchor region is a soluble and active enzyme retaining its substrate specificities. Biochim. Biophys. Acta 1771, 1457-1463

39 Heier, C. Taschler, U., Rengachari, S., Oberer, M., Wolinski, H., Natter, K., Kohlwein, S. D., Leber, R. and Zimmermann, R. (2010) Identification of Yju3p as functional orthologue of mammalian monoglyceride lipase in the yeast Saccharomyces cerevisiae. Biochim. Biophys. Acta 1801, 1063-1071

40 Yang, H., Bard, M., Bruner, D. A., Gleeson, A., Deckelbaum, R. J., Aljinovic, G., Pohl, T. M., Rothstein, R. and Sturley, S. L. (1996) Sterol esterification in yeast: a two-gene process. Science $\mathbf{2 7 2}, \mathbf{1 3 5 3 - 1 3 5 6}$

41 Abe, A. and Shayman, J. A. (1998) Purification and characterization of 1-0-acylceramide synthase, a novel phospholipase A2 with transacylase activity. J. Biol. Chem. 273 $8467-8474$

42 Abe, A., Hiraoka, M. and Shayman, J. A. (2006) Positional specificity of lysosomal phospholipase A2. J. Lipid Res. 47, 2268-2279

43 Peelman, F., Vinaimont, N., Verhee, A., Vanloo, B., Verschelde, J. L., Labeur, C., Seguret-Mace, S., Duverger, N., Hutchinson, G., Vandekerckhove, J. et al. (1998) A proposed architecture for lecithin cholesterol acyl transferase (LCAT): identification of the catalytic triad and molecular modeling. Protein Sci. 7, 587-599

44 Choudhary, V., Jacquier, N. and Schneiter, R. (2011) The topology of the triacylglycerol synthesizing enzyme Lro1 indicates that neutral lipids can be produced within the luminal compartment of the endoplasmatic reticulum: implications for the biogenesis of lipid droplets. Commun. Integr. Biol. 4, 781-784

45 Sikorski, R. S. and Hieter, P. (1989) A system of shuttle vectors and yeast host strains designed for efficient manipulation of DNA in Saccharomyces cerevisiae. Genetics 122 19-27 
SUPPLEMENTARY ONLINE DATA

\section{A novel pathway of ceramide metabolism in Saccharomyces cerevisiae}

Natalia S. VOYNOVA* ${ }^{*}$ Christine VIONNET ${ }^{*}$, Christer S. EJSING† and Andreas CONZELMANN*1

*Division of Biochemistry, Department of Biology, University of Fribourg, Chemin du Musée 10, Fribourg, CH-1700, Switzerland, and †Department of Biochemistry and Molecular Biology, University of Southern Denmark, Campusvej 55, DK-5230 Odense M, Denmark

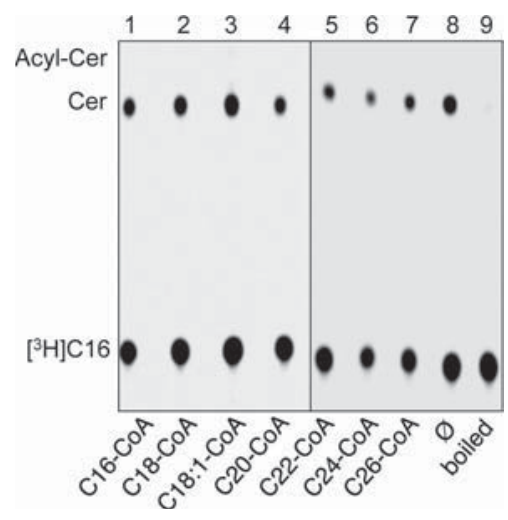

Figure S1 Dga1p does not contribute significantly to microsomal acylceramide synthesis in vitro

Microsomes of Iro1 $\Delta$ cells overexpressing YPC1 (Iro1 $\triangle$.YPC1) were incubated with PHS and [3H]palmitate to allow Ypc1p-driven ceramide synthesis to take place as in Figure 2(A), lane 8 of the main text. After a $1 \mathrm{~h}$ incubation, the reaction mixture was supplemented with different acyl-CoAs as indicated and samples were incubated for a further $1 \mathrm{~h}$ in conditions that are appropriate for Dga1p-mediated TAG synthesis. Lipids were extracted and resolved by TLC. Boiled microsomes were used for the incubation shown in lane 9. Cer, ceramide.

1 To whom correspondence should be addressed (email andreas.conzelmann@unifr.ch). 


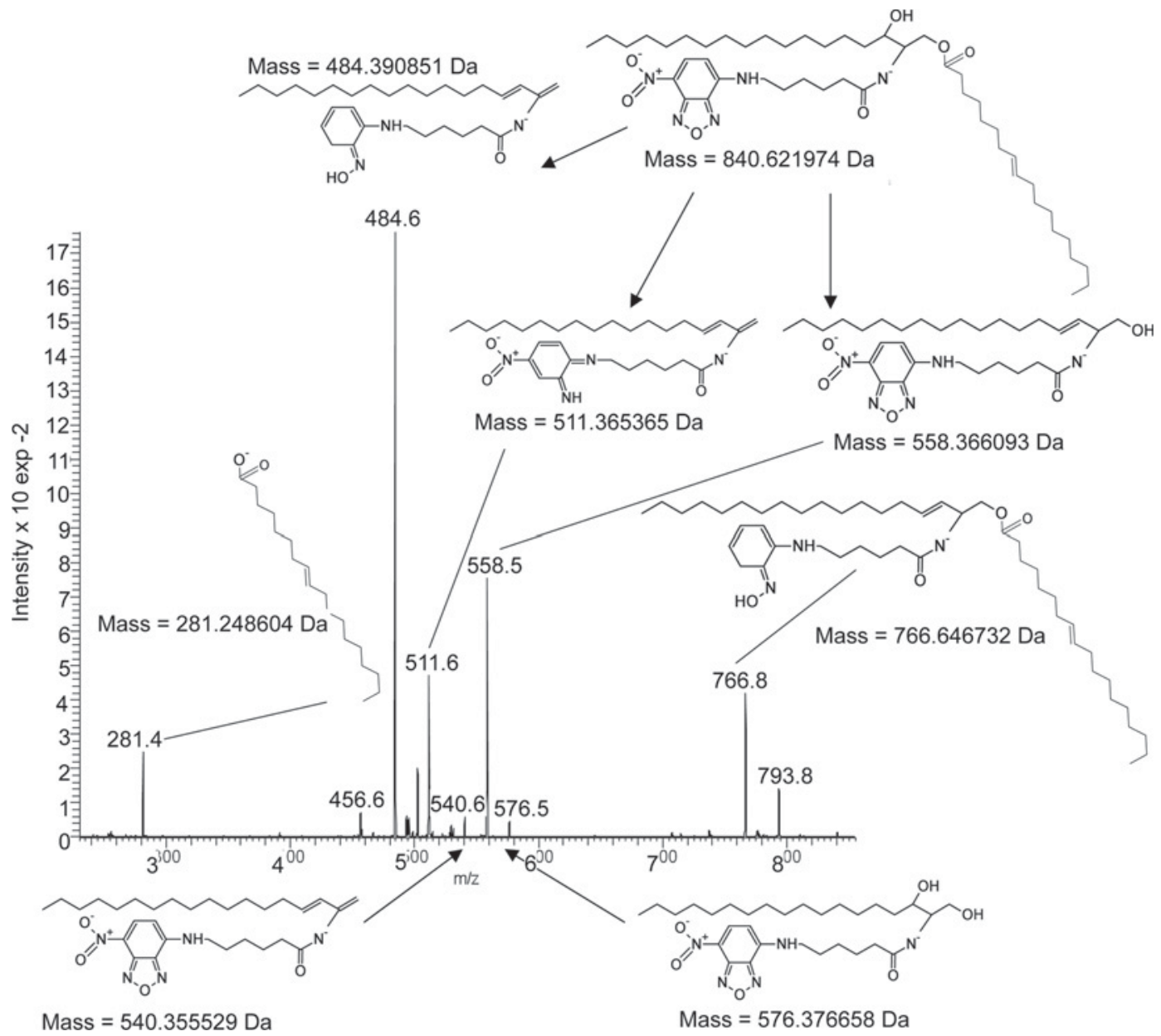

Figure S2 Structural analysis of $\mathrm{C}_{18: 1}-\mathrm{C}_{6}-\mathrm{NBD}-\mathrm{DHS}$ by ion-trap MS/MS

$\mathrm{C}_{18: 1}-\mathrm{C}_{6}-\mathrm{NBD}-\mathrm{DHS}$ ion at $\mathrm{m} / \mathrm{z} 840.6215$ detected in microsomes from wild-type cells incubated with $\mathrm{C}_{6}-\mathrm{NBD}-\mathrm{DHS}$ (Figure $5 \mathrm{~B}$ of the main text) was subjected to collision-induced dissociation. The $\mathrm{m} / \mathrm{z}$ of fragment ions in the resulting MS/MS spectrum confirm the identity of the $\mathrm{C}_{18: 1}-\mathrm{C}_{6}-\mathrm{NBD}-\mathrm{DHS}$ molecule as outlined in the fragmentation scheme.

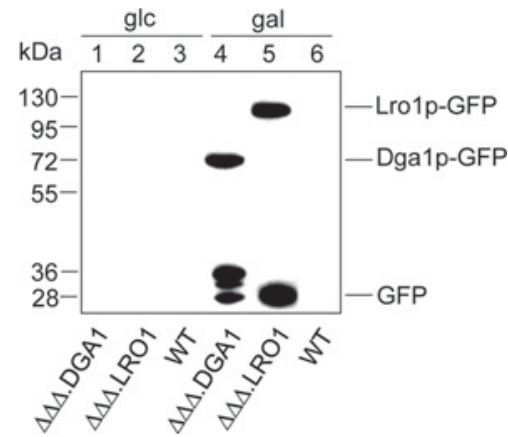

Figure S3 Galactose induces overexpression of LR01 or DGA1

Total cell lysate was prepared from are1 $\Delta$ are2 $\Delta$ Iro1 $\Delta . D G A 1 \quad(\Delta \Delta \Delta . D G A 1)$, are1 $\Delta$ are $2 \Delta$ dga1 $\Delta$. LR01 $(\Delta \Delta \Delta$. LR01) and WT strains grown overnight in galactose for the experiment shown in Figure $6(\mathrm{C})$ of the main text. The proteins were resolved by SDS/PAGE and detected by Western blotting using an anti-GFP antibody. The bands at $102 \mathrm{kDa}$ and $74 \mathrm{kDa}$ correspond to Lro1p-GFP and Dga1p-GFP respectively. The molecular mass in kDa is indicated. gal, galactose; glc, glucose. 

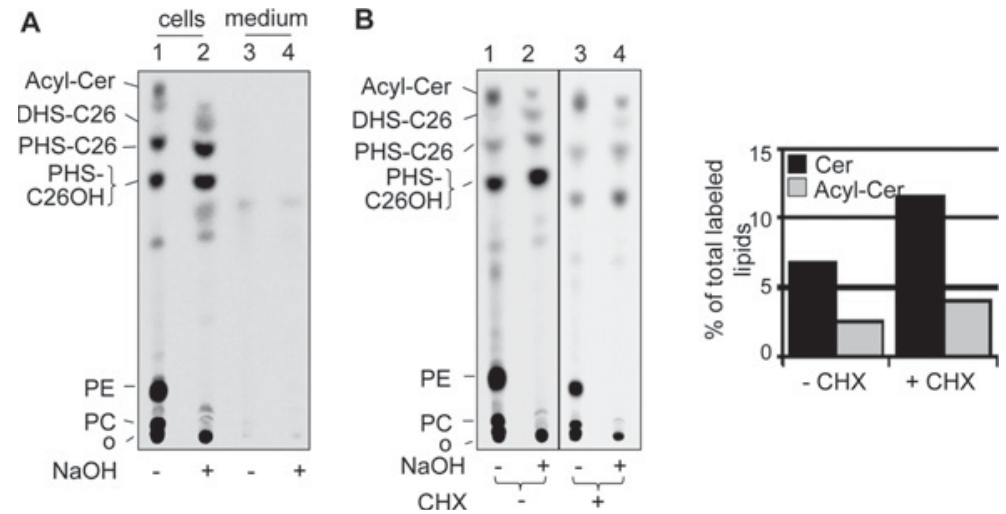

\section{Figure S4 Acylceramides are not secreted and also made in the absence of cycloheximide}

(A) Cells do not secrete acylceramides. WT cells were labelled with $\left[{ }^{14} \mathrm{C}\right]$ serine in the presence of $5 \mathrm{mg} / \mathrm{ml}$ fatty-acid-free BSA for $160 \mathrm{~min}$. The labelled lipids were extracted from cells and from medium; extracts were desalted, deacylated or not with sodium hydroxide and resolved by TLC. The Figure shows one of two experiments, which gave identical results. (B) CHX does not change the lipid profile of cells labelled with $\left[{ }^{14} \mathrm{C}\right]$ serine. WT cells were labelled with $\left[{ }^{14} \mathrm{C}\right]$ serine in medium supplemented with or without $10 \mu \mathrm{g} / \mathrm{ml} \mathrm{CHX}$ for $160 \mathrm{~min}$ at $30^{\circ} \mathrm{C}$. The extracted lipids were treated or not with mild base and resolved by TLC. The relative amounts of acylceramides and ceramides are shown on the right-hand side. Cer, ceramide; 0, origin.

A

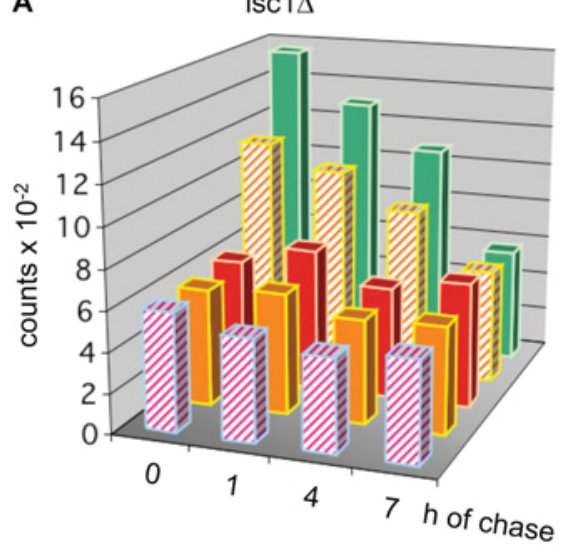

B WT

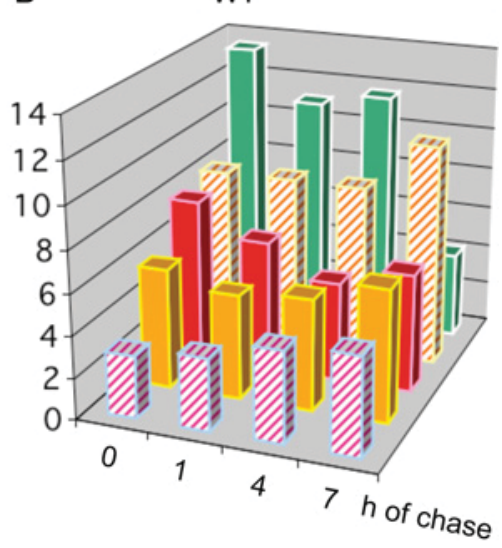

Phosphatidylethanolamine (PE)

(DHS-C26 + PHS-C26OH) after $\mathrm{NaOH}$

Acylceramides

Total ceramides before $\mathrm{NaOH}$

PHS-C26, after $\mathrm{NaOH}$

Figure S5 Quantification of TLC shown in Figure 8(C) of the main text

Berthold radioscanning yielded counts for each labelled species after $0,1,4$ and $7 \mathrm{~h}$ of chase in the presence of myriocin. Counts were plotted without any background subtraction except for acylceramides, for which the counts in the mild-base-resistant lanes at the $R_{\mathrm{f}}$ of acylceramides and the $R_{\mathrm{f}}$ of fatty acids were subtracted. (A) isc1 $\Delta$ cells. (B) WT cells.

Received 30 April 2012/12 June 2012; accepted 28 June 2012

Published as BJ Immediate Publication 28 June 2012, doi:10.1042/BJ20120712 